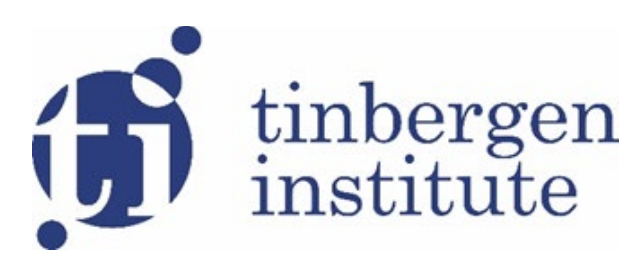

TI 2021-070/IV

Tinbergen Institute Discussion Paper

\title{
Do Financial Advisors Exploit Responsible Investment Preferences?
}

\author{
Utz Weitzel ${ }^{1}$ \\ Marten Laudi ${ }^{2}$ \\ Paul Smeets ${ }^{2}$
}

\footnotetext{
${ }^{1}$ Vrije Universiteit Amsterdam

2 Maastricht University
} 
Tinbergen Institute is the graduate school and research institute in economics of Erasmus University Rotterdam, the University of Amsterdam and Vrije Universiteit Amsterdam.

Contact: discussionpapers@tinbergen.nl

More TI discussion papers can be downloaded at https://www.tinbergen.nl

Tinbergen Institute has two locations:

Tinbergen Institute Amsterdam

Gustav Mahlerplein 117

1082 MS Amsterdam

The Netherlands

Tel.: +31(0)205984580

Tinbergen Institute Rotterdam

Burg. Oudlaan 50

3062 PA Rotterdam

The Netherlands

Tel.: +31(0)10408 8900 


\title{
Do Financial Advisors Exploit Responsible Investment Preferences?
}

\author{
Marten Laudi* $\quad$ Paul Smeets ${ }^{\dagger} \quad$ Utz Weitzel $^{\ddagger \S}$
}

July, 2021

\begin{abstract}
An unprecedented number of investors are giving their financial advisors a mandate for socially responsible investing (SRI). Yet, the impact of SRI mandates on consumers is unclear. In a pre-registered lab-in-the-field experiment with 345 professional advisors, we find that advisors charge a premium to SRI clients that cannot be justified by higher effort, skill, or costs. This suggests that advisors exploit the SRI preferences of their clients (who accept these higher fees). In an independent survey, financial regulators predict higher SRI fees but do not predict exploitation. Regulators confirm that our findings are externally valid and require attention from policymakers.
\end{abstract}

JEL Classification: C93, G11

Keywords: Experimental Finance, Financial Advice, Socially Responsible Investments.

*Maastricht University, School of Business and Economics [m.laudi@maastrichtuniversity.nl]

${ }^{\dagger}$ Maastricht University, School of Business and Economics [pm.smeets@maastrichtuniversity.nl]

${ }^{\ddagger}$ Vrije Universiteit Amsterdam \& Tinbergen Institute [u.weitzel@vu.nl]

$\S_{\text {Radboud University }}$

The study was pre-registered at https://www . socialscienceregistry.org/trials/6026 and was ethically approved by the Ethical Review Committee Inner City faculties (ERCIC) at Maastricht University under the reference: ERCIC_173_27_01_2020. The study was financially supported by the Graduate School of Business and Economics at Maastricht University, VU Amsterdam, and Radboud University. Paul Smeets is supported by a Veni grant from the Dutch Science Foundation under grant number 016.Veni.175.019. We thank (in alphabetical order) Rob Bauer, Dirk Broeders, Thomas Dirkmaat, Stan Dupre, Sascha Füllbrunn, Samuel Hartzmark, Anita Kopányi-Peuker, Christine Laudenbach, Michiel van Megen, Sven Nolte, Jan Schmitz, Colin Tissen, Mukul Tyagi, Stefan Zeisberger, Wilte Zijlstra, as well as participants of seminars and conferences at Maastricht University, Radboud University, The University of Kassel, Aston Business School, and the Society for Experimental Finance for helpful comments and suggestions. 


\section{Introduction}

Socially responsible investing (SRI) has surged in volume in the US and one in three dollars of the total US assets under management use SRI strategies (USSIF, 2020). Much of this growth in SRI is driven by individuals' social preferences, as investors derive non-pecuniary utility from their investments (Białkowski \& Starks, 2016; Hartzmark \& Sussman, 2019; Humphrey, Kogan, Sagi, \& Starks, 2020; Bauer, Ruof, \& Smeets, 2021; Heeb, Kölbel, Paetzold, \& Zeisberger, 2021). Social preferences often translate into a willingness to pay for SRI products by accepting lower expected financial returns (Barber, Morse, \& Yasuda, 2021) or by accepting higher fees (Riedl \& Smeets, 2017) on socially responsible investments.

Investors guided by their social preferences can contribute to reaching the United Nations Sustainable Development Goals (SDGs). Their investments can help in the allocation of capital to companies and projects that positively contribute to society. However, socially responsible investors with a high willingness to pay for SRI also run the risk of being exploited by financial professionals. Regulators, such as the European Securities and Markets Authority (ESMA), are concerned that financial advisors may take knowledge about clients' SRI preferences "as an excuse to sell own-products or more costly ones." ${ }^{1}$ Consumer organizations share this concern with regulators. ${ }^{2}$ The potential for such exploitation of social preferences could further increase in Europe in the future. A forthcoming amendment to the Markets in Financial Instruments Directive II (MiFID II) of the European Union will require financial advisors to ask clients whether they want to give an SRI mandate. ${ }^{3}$ The majority of professional asset managers claim that they are unaware of any conflicts of interest linked to clients' SRI preferences, pointing out that the management of SRI products "can - by nature - be more costly than their non-ESG

\footnotetext{
${ }^{1}$ See ESMA's technical advice to the European Commission on integrating sustainability risks and factors in MiFID II (ESMA35-43-1737, 30 April 2019, p.15): https://www.esma.europa.eu/sites/ default/files/library/esma35-43-1737_final_report_on_integrating_sustainability_risks _and_factors_in_the_mifid_ii.pdf

${ }^{2}$ See Points 24 on p.14 and Point 27 on pp.14/15 in the ESMA report (ESMA35-43-1737, 30 April 2019)

${ }^{3}$ https : //eur-lex.europa.eu/legal-content/EN/TXT/PDF/?uri=CELEX : 52018DC0097\&from=EN

${ }^{4} \mathrm{ESG}$ stands for Environmental, Social, and Governance and is used interchangeably with SRI in this context.
} 
equivalents, related for instance to the cost of ESG screenings and scoring of underlying stocks." 5

In this study, we investigate the two main questions that arise from this debate on the potential exploitation of clients with a preference for socially responsible investments. First, do financial professionals charge higher fees for SRI mandates? Second, if so, does this mean that financial advisors exploit the knowledge about their clients' SRI preferences? Empirically, the answer to the two questions is not trivial. By definition, SRI portfolios differ in their composition from conventional portfolios, which makes it difficult to compare fees for funds and services across mandates. The scant empirical evidence is mixed, ranging from significantly higher fees for SRI funds (Shanker, 2019; Cao, Titman, Zhan, \& Zhang, 2020; Raghunandan \& Rajgopal, 2021) to no difference in fees compared with conventional funds (Gil-Bazo, Ruiz-Verdú, \& Santos, 2010).

Further, even if the fees for SRI mandates are higher, this could be reasonably explained by higher costs (e.g., if more effort goes in screening) and/or higher service quality (e.g., if more skilled professionals select into SRI). We can only infer a possible conflict of interest and exploitative behavior if advisors charge higher fees in the absence of qualitatively better or more costly SRI services. With archival data, however, it remains an empirical challenge to disentangle the two factors and find an identification strategy that provides reliable causal evidence for exploitative behavior.

We therefore conducted a pre-registered online lab-in-the-field experiment, in which we control for possible reasons for higher SRI fees. In our experiment, we replicate an advisor - client relationship with real financial advisors and real clients, who invest real money in the stock market. As advisors, we recruited a sample of 345 professional financial advisors in the US who are involved in managing or brokering financial assets on behalf of clients in their professional life. ${ }^{6}$ As (retail) clients, we recruited a sample of individuals from the US who invest money in the stock market and are not financial professionals. The experimental design mimicked the most important features of the

\footnotetext{
${ }^{5}$ See Point 23 on p.14 in the ESMA report (ESMA35-43-1737 of 30 April 2019)

${ }^{6}$ We included, for example, private bankers, investment advisors, and portfolio managers, but not IT support, auditors, or professionals in corporate finance.
} 
participants' natural decision environment and consists of two stages.

In the first stage, the advisors managed a stock portfolio for their client with an investment budget of $\$ 1,000$. The advisors had access to basic information about their client's profile, including age, gender, income bracket, and risk appetite, as well as the client's investment mandate (conventional or SRI). After seeing the client profile and mandate, the advisors allocated their client's budget by assigning a weight between 0 and $100 \%$ to all 30 stocks in the Dow Jones Industrial Average. When making these portfolio decisions, advisors had access to financial information and SRI ratings for each stock. Our main outcome variable is the fee that advisors set for their service as a percentage (between 0 and 4\%) of the total invested amount. For example, a fee of $2.3 \%$ on $\$ 1,000$ would correspond to $\$ 23$.

In the second stage of the experiment, clients were matched to advisors. The client decided whether to take the service of the advisor and pay the fee set by the advisor or to make her own investment decision. Hence, advisors needed to set a fee that was attractive enough for their client to accept their service. We implemented the chosen portfolio by purchasing the selected stocks in the market (for one year). The clients either earned the raw portfolio return (self-selected portfolio) or a net return after fees (advisor's portfolio). Hence, all participants' decisions were consequential. The amount we invested in each stock solely depended on the decisions made by the participants, who were fully informed about their payoff structure ex ante. ${ }^{7}$

Each advisor saw four different client profiles. Our primary treatment variable was client mandate: SRI in two profiles and conventional in the other two. Given the importance of client gender in the previous literature on financial advice, we used a secondary treatment variable by changing gender across mandates. Each advisor saw one SRI mandate (conventional mandate) from a female client and one from a male client $^{8}$. The different decisions of advisors allow us to control for advisor fixed effects that pick up potential differences in advisor quality, knowledge, or general effort levels.

\footnotetext{
${ }^{7}$ After the experiment, the participants were also able to receive proof of all stock transactions.

${ }^{8}$ To facilitate our advisor - client matching procedure, we only included clients who selected "Male" or

"Female" as gender and excluded clients who selected "Other."
} 
Our results show that financial advisors create more socially responsible portfolios for clients with SRI mandates. However, they also charge a higher advisory fee for clients with an SRI mandate of 4.9 to 6.7 basis points (depending on the type of analysis). Although the primary goal of our experiment is to provide causal inference for revealed SRI preferences and not to estimate exact effect sizes, it is intriguing to quantify the potential market-wide effects of the fee differences. A back-of-the-envelope analysis suggests that, in 2020, individual/retail SRI clients paid excess fees of at least $\$ 2.23$ billion in the US alone. If we apply the same premium to all US funds using SRI strategies (including institutional investors), excess fees in 2020 were $\$ 8.38$ billion. $^{9}$ Even if our effect size is just an indication we consider this premium to be economically meaningful.

In our experiment, we find no difference in the time or effort spent by advisors for SRI clients versus conventional clients. Moreover, our experiment was designed such that SRI screening information was free to advisors, which rules out fee differences related to costs of buying SRI data, an argument often raised by financial professionals in the field. In this setting we can therefore infer from the higher fee for SRI clients that an intent exists for price discrimination that exploits clients' responsible investing preferences.

Even if advisors charge higher fees for SRI without exerting more effort, it is not a given that this behavior would survive in a market where clients have a choice not to take the advice. We therefore check how often clients in our experiment accept the fees for their mandates. Socially responsible clients are equally likely to take on the advice as are conventional clients, even if they are charged a higher fee. ${ }^{10}$

The results further show weak evidence of exploitation based on gender. Previous studies have shown that the costs and content of financial advice can depend on a client's gender. Advisors may assume that women are financially less literate, which can lead advisors to charge higher fees to women (Baeckström, Silvester, \& Pownall, 2018; BucherKoenen, Hackethal, Koenen, \& Laudenbach, 2019; Bhattacharya, Kumar, Visaria, \&

\footnotetext{
${ }^{9}$ For this, we multiply our most conservative fee premium (4.9 basis points) with US SIF's 2020 estimate of SRI funds that were invested by money managers on behalf of individual/retail investors $(\$ 4.55$ trillion) and on behalf of all US SRI investors (\$17.1 trillion).

${ }^{10}$ This is in line with studies that report a large and persisting dispersion in fees for comparable products in retail financial markets (Brown \& Goolsbee, 2002; Hortaçsu \& Syverson, 2004; Bergstresser, Chalmers, \& Tufano, 2008; Carlin, 2009).
} 
Zhao, 2020). Our results hint toward the opposite, indicating a tendency of advisors to spend more time and effort on women while charging them lower fees. However, all gender effects are only marginally significant.

We run several tests to check the internal validity of our results. Our results are robust to different model specifications. ${ }^{11}$ We perform four other robustness checks. First, we exclude participants who took less than five minutes to complete the experiment. Second, we exclude all participants who did not answer general attention check questions correctly throughout the study. Third, we asked comprehension questions about the experimental design and excluded all participants who answered one or more of them incorrectly. Fourth, financial professionals in our sample have different job types (e.g., private bankers, investment advisors, or portfolio managers). Some job types may be more strongly involved in financial advice than others. For robustness, we exclude account managers and customer support, who are less directly related to advice. All reported results are robust to these exclusions and often become even stronger with the reduced sample. We report the more conservative results of the full sample throughout the paper.

The strength of experiments lies in providing clean evidence for causal relations. Labin-the-field experiments related to social preferences have predictive power for real world financial decisions (Karlan, 2005; Riedl \& Smeets, 2017). However, experiments are also, by nature, a simplification of a more noisy reality. Thus, even if our results are internally robust in the sense that they hold for this setting, the question remains whether the results are also externally valid and informative for real advisor-client relationships. In the design of our experiment we therefore incorporated important contextual elements of advisors' natural decision-making environment, which we pre-tested with a different group of financial professionals, for example, the set of financial information needed for the portfolio selection. Our study thereby falls in the category of a framed field experiment (Harrison \& List, 2004). Recruiting financial professionals as participants increases the external validity, as financial professionals have frequently been shown to

\footnotetext{
${ }^{11}$ We re-run our main analysis in a Tobit model that accounts for the possibility that the data are censored (fees were bounded between 0 and 4\%). Further, fee differences remain significant when including all available client characteristics.
} 
behave differently from student participants (Haigh \& List, 2005; Alevy, Haigh, \& List, 2007; Kaustia, Alho, \& Puttonen, 2008; Roth \& Voskort, 2014; Kirchler, Lindner, \& Weitzel, 2018; Weitzel et al., 2020).

To further test the external validity of our results, we collected survey data from 53 professionals who are concerned with regulation, policymaking, compliance, and supervision in the financial sector (henceforth, regulators). After providing the experimental instructions, we asked the regulators whether they believe that the findings from our research study are informative about the behavior of financial advisors in the field. In total, $77 \%$ considered our study to be informative or very informative for the US, and only $7.5 \%$ rated our results as not informative or hardly informative.

Lab-in-the-field experiments can be a powerful tool to inform public policy (Levitt \& List, 2009; Gneezy \& Imas, 2017), but hindsight bias may lead policymakers and regulators to conclude that results are "obvious" ("I knew this already") (DellaVigna, Pope, \& Vivalt, 2019). Therefore, we asked the regulators to predict the outcome of our study (incentivized). They correctly predicted that the advisors in our experiment demand higher fees for SRI clients. However, they also expected the advisors to spend more effort on managing SRI portfolios. Thus, the regulators seem to think that socially responsible investors pay a premium in exchange for an extra service. Yet, our results show that a conflict of interest does exist, and the advisors do not exert any more effort for the premium they charge clients with a socially responsible mandate. The regulators also incorrectly predicted higher fees and lower effort for female clients compared to male clients. Our results indicate the opposite, but also show that SRI mandates drive up fees significantly more than clients' gender.

When confronted with the observed results of our study, a majority ( $81 \%$ of the regulators) stated that the results from our experiment require attention from policymakers. When we asked the regulators to suggest suitable policy interventions, they mostly mentioned transparency (30\%), standardization of fees (25\%), and consumer education $(17 \%)$.

We rule out the possibility that the regulators may have misunderstood our design. 
Further, the results from the regulator survey are robust to only considering regulators who report that they have work experience with SRI-related projects or topics.

Our study contributes to the growing literature on SRI, ${ }^{12}$ particularly to studies that investigate possible differences in fees between SRI and conventional funds. Some media outlets proclaim SRI as the new cash cow, where up to $42 \%$ higher fees can be earned with no extra costs. ${ }^{13}$ In the academic literature, the evidence is ambiguous. Some studies find no difference in fees (Gil-Bazo et al., 2010), while others report significantly higher fees for SRI funds (Shanker, 2019; Cao et al., 2020; Raghunandan \& Rajgopal, 2021). We contribute to this debate by showing that SRI fees are, indeed, higher in our setting, not because of higher effort, skill, or costs but because of exploitation.

Our paper also provides insights into the advisor - client relationships in the market for financial advice. A range of studies show that conflicts of interest between financial advisors and their clients often benefit advisors who offer self-serving advice (Bergstresser et al., 2008; Hackethal, Haliassos, \& Jappelli, 2012; Hoechle, Ruenzi, Schaub, \& Schmid, 2018; Egan, 2019; Chalmers \& Reuter, 2020). We add to this by showing that advisors also exploit information about clients' SRI preferences to selectively set fees.

Our work further contributes to the policy debate on the elicitation of responsible investment preferences. The European Commission states that "the financial sector has a key role to play in reaching these fundamental environmental and social goals." ${ }^{14}$ To foster SRI, the European Commission formulated an action plan to redirect financing towards sustainable growth. ${ }^{15}$ Part of this action plan will require financial institutions to ask clients whether they want to give a mandate for SRI. An unintended consequence of this action plan might be that advisors would use knowledge about their clients' responsible investment preferences to overcharge them. In equilibrium, socially responsible investors

\footnotetext{
${ }^{12}$ See Benson and Humphrey (2008); Hong and Kacperczyk (2009); Białkowski and Starks (2016); Riedl and Smeets (2017); Hartzmark and Sussman (2019); Pedersen, Fitzgibbons, and Pomorski (2020); Gibson, Glossner, Krueger, Matos, and Steffen (2020); Krueger, Sautner, and Starks (2020); Bauer et al. (2021)

${ }^{13}$ Wursthorn, M. (2021). Tidal wave of ESG funds brings profit to Wall Street. The Wall Street Journal. Retrieved from https://www.wsj.com/articles/tidal-wave-of -esg-funds-brings-profit-to-wallstreet-11615887004

${ }^{14}$ https : //eur-lex.europa.eu/legal-content/EN/TXT/PDF/?uri=CELEX : 52018DC0097\&from=EN, p.13

${ }^{15}$ https : //eur-lex.europa.eu/legal-content/EN/TXT/PDF/?uri=CELEX : 52018DC0097\&from=EN
} 
are already expected to receive lower financial returns (Pástor, Stambaugh, \& Taylor, 2020). The higher fees would come on top, threatening the long-run attractiveness of responsible investing.

\section{Study design}

The study was pre-registered at the AEA RCT Registry ${ }^{16}$ and ethically approved by the Ethical Review Committee of University of Maastricht University. The experiment consisted of two stages, administered separately to advisors and to clients, which we will refer to as the advisor stage and the client stage.

\subsection{Advisor stage}

In this stage, the advisors saw a client profile, selected stocks on behalf of that client with an investment budget of $\$ 1,000$, and set an advisory fee for their service. The full instructions for advisors are shown in section B.1.

\subsubsection{Client profiles}

For each client, the advisors received information regarding gender, income, age, risk preferences, and investment mandate. Figure 1 shows an example of the information we provided per client. As the main treatment variable, each client profile showed an investor mandate (conventional or socially responsible), which we combined with a pop-up window for more salience and explanation. Each advisor saw the profile of one female SRI client, one male SRI client, one female conventional client, and one male conventional client. The order in which these client profiles were shown was randomized and balanced across advisors. Age was randomized for each client profile to be either between 35 and 44 years old or between 45 and 54 years old. Gross income was randomized for each client profile to be either between $\$ 40,000$ and $\$ 59,999$ or between $\$ 60,000$ and $\$ 79,999$ per year. To make sure that the advisors could allocate all funds into equity and that clients' risk

\footnotetext{
$\overline{{ }^{16} \text { see https://www.socialscienceregistry.org/trials/6026 }}$
} 
preferences were not driving our results, we only recruited clients with an aggressive risk profile, who stated that they were willing to invest $100 \%$ of their experimental investment budget into stocks.

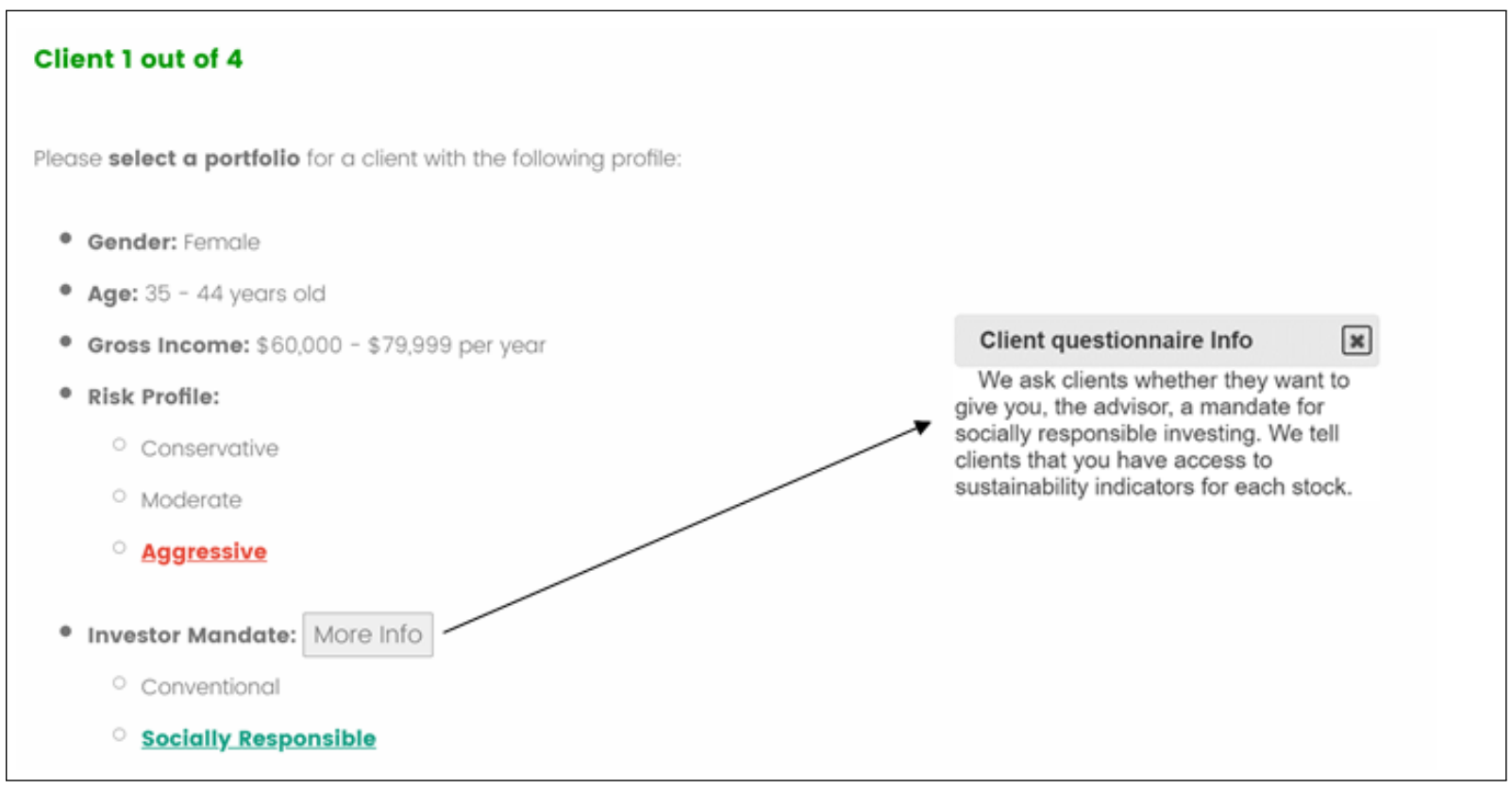

Figure 1: Client profile screenshot (Advisor stage)

\subsubsection{Stock information and selection}

Below the client profile information, on the same screen, the advisors were asked to select a portfolio for this client by assigning a weight between 0 and $100 \%$ to all 30 stocks in the Dow Jones Industrial Average. For each stock, we provided the advisors with two indicators for social responsibility of investments, which were explained in more detail with pop-up windows (see Figure 2).

One indicator for social responsibility was a firm's MSCI ESG score, which is commonly used in academic publications and practice. The MSCI ESG indicator is a letter rating, ranging from AAA to CCC. In line with the classification on the MSCI ESG website, we color-coded and named the letter classifications as follows: CCC and B were shown in gray (labeled "laggard"); BB, BBB, and A were shown in yellow (labeled "average"); AA and AAA were shown in green (labeled "leader").

We also included a binary indicator, which showed whether or not a firm was a participant of the United Nations Global Compact (GC). Participants of the United Nations 
GC pledge to implement sustainable and socially responsible practices and to report on their progress. Also, United Nations GC participants pledge to operate responsibly, in alignment with the United Nations' sustainability principles in the areas of human rights, labor, the environment, and anti-corruption. We color-coded United Nations GC participating companies with a green letter "Y" (for yes) and with a black letter "N" (for no).

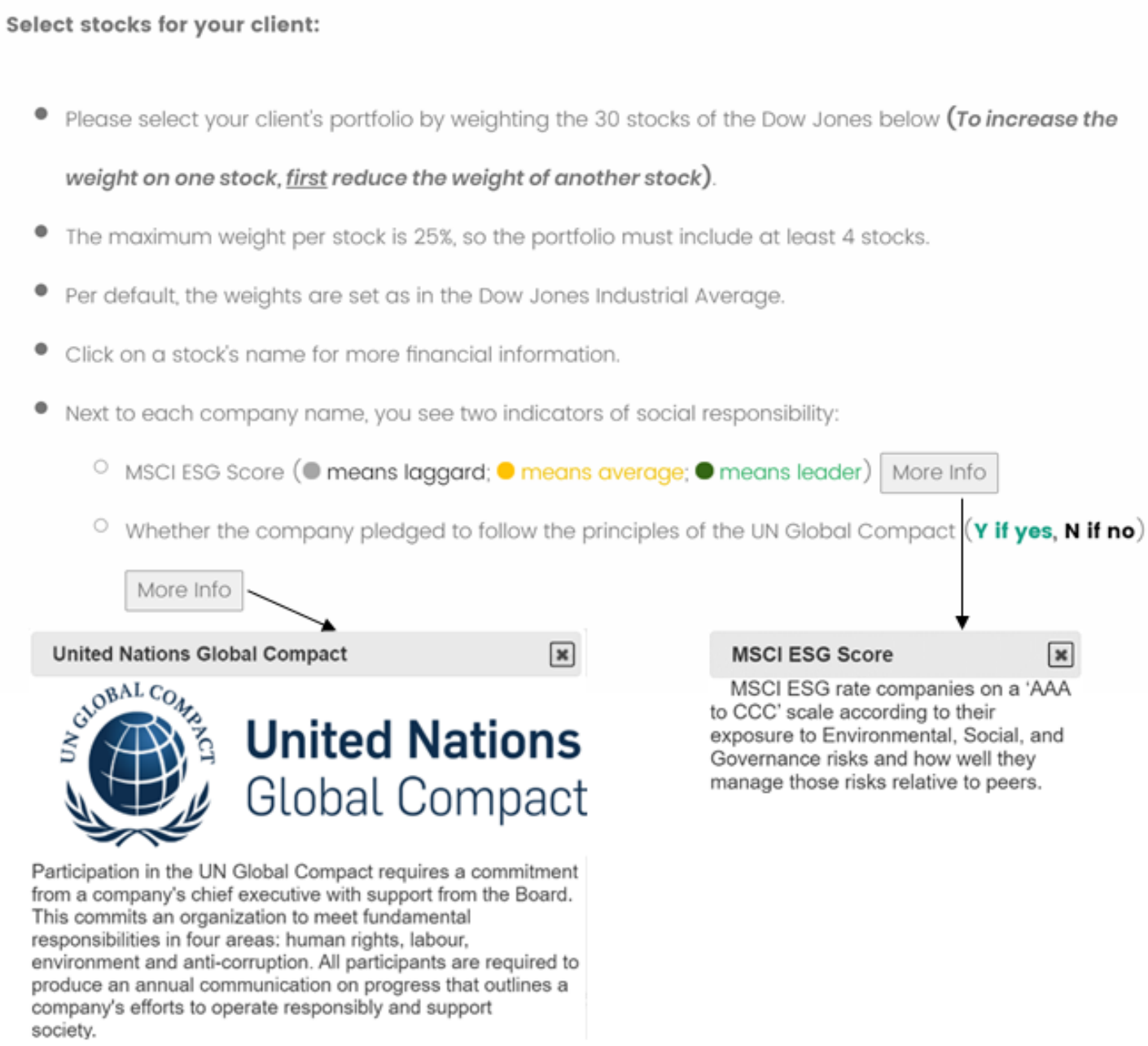

Participation in the UN Global Compact requires a commitment from a company's chief executive with support from the Board. This commits an organization to meet fundamental responsibilities in four areas: human rights, labour, environment and anti-corruption. All participants are required to produce an annual communication on progress that outlines a company's efforts to operate responsibly and support society.

Figure 2: Portfolio screenshot 1 (Advisor stage)

For each stock, we also provided key financial information. To create a representative decision environment and, at the same time, prevent information overflow, we ran a preselection to determine what financial information to show. In this pre-selection, we asked financial professionals, who were not part of the main study, what information they primarily use in their decision-making process. ${ }^{17}$ On the decision screen we displayed

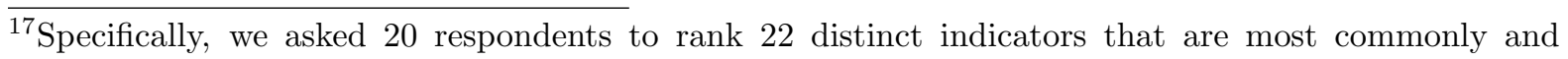


the six most important financial indicators. As an example, Figure 3 shows the pop-up window with the financial information that appears when clicking on Verizon.

Based on this information, the advisors weighted all 30 stocks in the Dow Jones Industrial Average for the client. The order of the 30 stocks was randomized across advisors. By default, the weight per stock was set as in the Dow Jones Industrial Average, which the advisors were able to adjust with a slider (or by entering the weight directly). At the bottom of the table, we displayed the total of all weights. The advisors were only able to proceed if that total was exactly 100. The example in Figure 3 shows the weighting of eleven stocks at the bottom of the list of 30 .

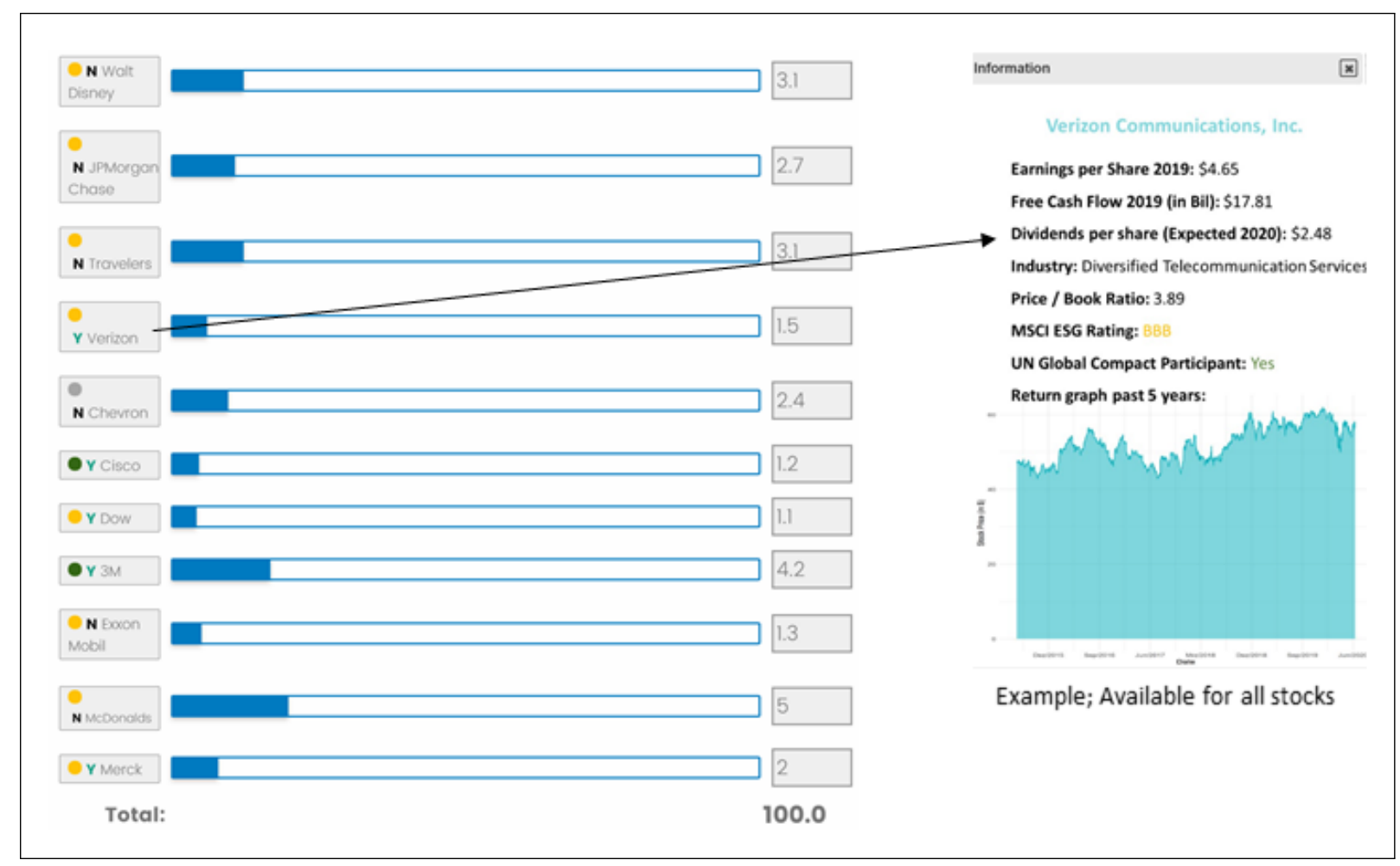

Figure 3: Portfolio screenshot 2 (Advisor stage)

\subsubsection{Advisor fee and payment relevance}

After selecting stocks for a specific client profile, the advisors were asked to set a fee for this service. They did this on a slider with no anchor (see Figure 4). They could set the fee to any percentage between 0 and 4\%. This range includes any realistic advisory fee.

prominently displayed on platforms such as Morningstar, Yahoo! Finance, Fidelity, and CNN Money according to their importance in selecting portfolios of stocks. See section B.3 for full instructions and Table A1 for the indicators that were ranked to be most important. 
Having a broader range would have made it difficult for the advisors to select a specific fee.

The advisors set a fee for each of the four client profiles. At the end of this stage, we randomly picked one of the four client profiles, which was relevant for the advisor payment. The portfolio allocation and fee for this client profile were shown to a real client in the second experimental stage.

Advisory fee for your client as a percentage of the $\$ 1,000$ portfolio value: Based on this fee, your client will decide whether to see your advice or to make her own investment.

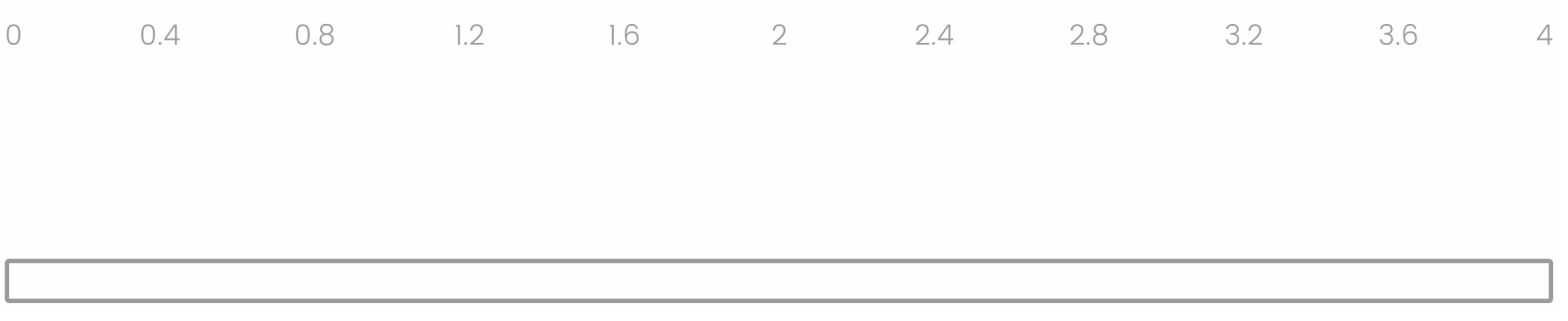

Figure 4: Fee setting screenshot (Advisor stage)

\subsection{Client stage}

Once the advisor stage was completed, we sampled clients who matched the randomly selected client profiles from the advisor stage. For this, we administered screening questions on age, gender, income, risk taking, and investor mandate (see section 2.5 for more details). If a client matched one of the payment-relevant profiles of one of the advisors, the client was informed that she would receive an investment budget of $\$ 1000$ to be invested in the stock market and that a financial advisor has selected a portfolio of stocks. The clients saw the instructions that were given to the advisors as well as an example portfolio selection screen from the advisor stage. We then asked the clients comprehension questions about the advisor stage.

The clients then saw the fee that their advisor set for selecting the portfolio (See Figure 5) and decided to either pay the fee and take the advice or not to pay the fee and select their own portfolio of stocks. In the latter case, the clients went through the same stock selection process as the advisors. The advisors were paid out according to their 
matched client's decision.

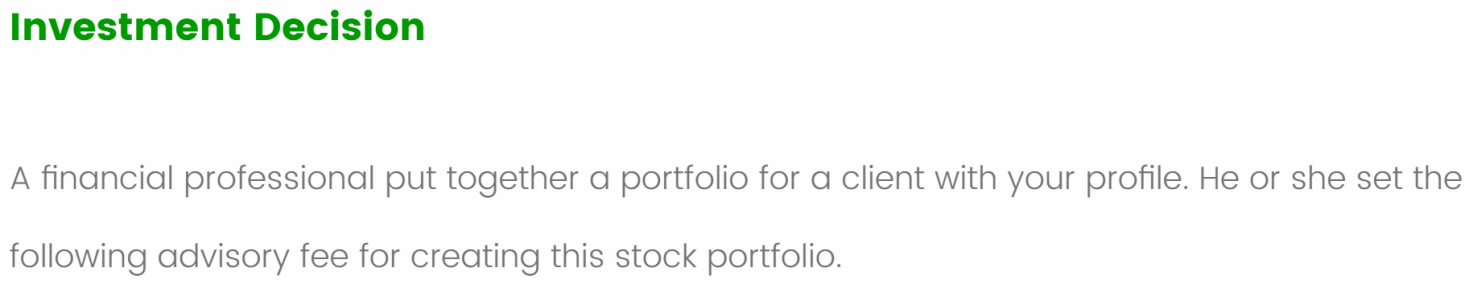

Advisory Fee: $1.4 \%$

Would you like to invest in the stock portfolio that your advisor constructed on your behalf?

\section{Yes, I will take the advice}

\section{No, I will select stocks myself}

\section{Figure 5: Investment decision screenshot (Client stage)}

\subsection{Payment}

All participants received a small show-up fee plus a variable payment that was contingent on their decisions in the experiment. ${ }^{18}$

For the advisors, the additional payment depended on whether or not the client took the advice. Advisor j received:

$$
\Pi_{j}= \begin{cases}\rho+\text { Advisory } f e e_{i}, & \text { if client } i \text { selects the advisor portfolio } \\ \rho, & \text { otherwise }\end{cases}
$$

where $\Pi_{j}$ refers to the payoff to advisor $\mathrm{j}$, and $\rho$ refers to the show-up fee. The advisory fee was set as a percentage of the $\$ 1,000$ investment budget of clients, so an advisory fee of $1.4 \%$ corresponded to a payment of $\$ 14$.

\footnotetext{
${ }^{18}$ The show-up fee of $\$ 2$ was equal for advisors and clients and was offered on top of an undisclosed show-up fee that the market research company pays to all its clients for completed surveys.
} 
For clients, the variable payment depended on the performance of the selected investment. Every $10^{\text {th }}$ client (randomly selected) received a variable payment. Clients who were not randomly selected received the show-up fee $\rho$. If randomly selected, client $\mathrm{i}$ received:

$$
\Pi_{i}= \begin{cases}\rho+\$ 150-\text { Advisory } f e e_{i}+r_{j}, & \text { if client } i \text { selects the advisor portfolio } \\ \rho+\$ 150+r_{i}, & \text { otherwise }\end{cases}
$$

The variable payment included a base payment of $\$ 150$. If the clients chose to view the advice, the advisory fee was deducted from this. Additionally, we recorded the return of their chosen investment over the coming year. If a client took the advice, their payment depended on the performance of the advisor portfolio $r_{j}$. If a client did not take the advice, their payment depended on the performance of the portfolio they selected themselves, $r_{i}$. While overall earnings could not be lower than zero, the clients participated in gains as well as losses of selected stock portfolios due to the $\$ 150$ base payment.

\subsection{External consequences of decisions}

We ensured that our experiment was consequential. Previous experimental studies have shown that participants' behavior differs in real versus hypothetical situations (List \& Gallet, 2001). This is especially relevant in our setting, where socially responsible investors care about the societal impact of purchasing stocks. We therefore ensured that the participants' decisions were consequential by purchasing stocks on the market, depending on the decisions that were made by participants. For one in ten participants, we purchased and held stocks according to the participant's selection until the end of the investment horizon (after one year). The participants were informed about this. Proof of all stock transactions that we made to implement the portfolios are available to participants. ${ }^{19}$ We aggregated and anonymized all participant data to make it impossible to trace back any decision made in the experiment.

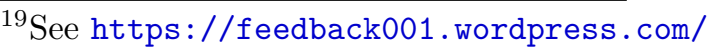




\subsection{Implementation}

Our data collection took place in the second half of 2020, with the implementation of the stock portfolios on December 11, 2020. All experimental stages were administered online with Qualtrics. We collected the data in collaboration with the market research agency Dynata. $^{20}$

As advisors, we recruited finance professionals in the US, whom we selected on the basis of two screenings. The first screening asked the participants to report their industry sector. We only included those who selected financial services (e.g., banks and insurance companies). In the second screening, we filtered out all participants whose job did not involve managing or brokering financial assets on behalf of clients in their professional life. We included, for example, private bankers, investment advisors, and portfolio managers, but not IT support, auditors, or those working in corporate finance. As clients, we recruited a sample of individuals from the US (see Figure A1). To match clients to the profiles that we presented to the advisors, we screened out clients whose annual household income was below $\$ 40,000$ or above $\$ 79,999$ or whose age was below 35 or above 54 . Also, we asked the clients about their risk preferences in investing and only selected those who were willing to invest their entire experimental investment budget in stocks. Finally, we asked the clients about their investor mandate in order to create a match with the respective profile shown to the advisor. ${ }^{21}$

Our sample included 345 advisors from 45 different states in the US (see Figure 6). Since every advisor created a portfolio and set a fee on behalf of four different clients, we observed a total of 1,380 client-advisor relationships. Table A2 gives an overview over the characteristics of the sample.

\footnotetext{
${ }^{20}$ Dynata has access to more than 62 million consumers and business professionals and is specialized in B2B surveys, with over 40 years of experience in this area.

${ }^{21}$ Specifically, we ask clients: Do you want to give your advisor a mandate for socially responsible investing?
} 


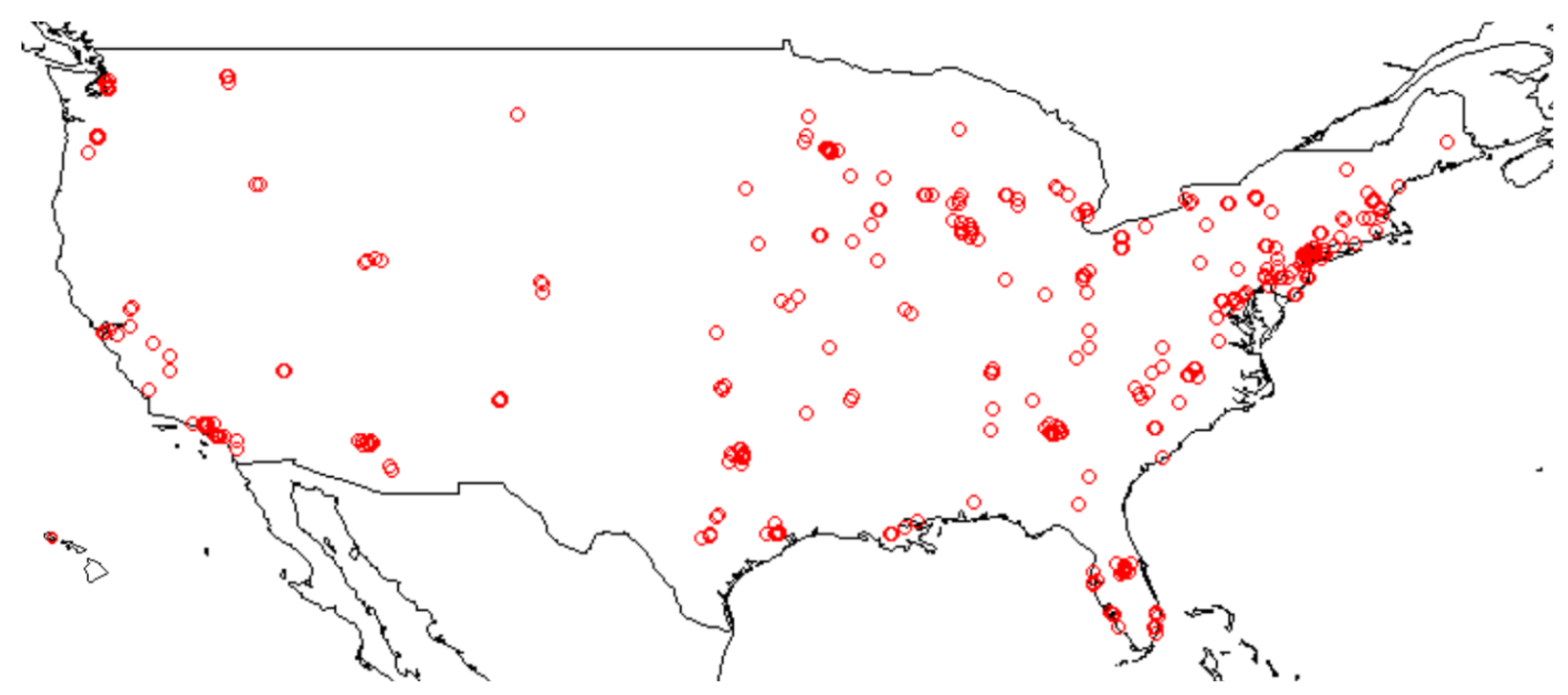

Figure 6: Location of advisors

\section{Results}

\subsection{Advisors create more socially responsible portfolios for clients with an SRI mandate}

We first consider whether the advisors take SRI mandates of clients seriously. Table 1 shows the outcome of four OLS regressions with advisor fixed effects. Each column has a different indicator of social responsibility as a dependent variable. The dependent variable of the first regression, United Nations GC of client i, is defined as:

$$
\text { United Nations } G C_{i}=\sum\left(\text { Weight of stock } k(\text { in } \%) * \text { United Nations } G C_{k}\right) \text {, }
$$

where United Nations $G C_{k} \epsilon\{0 ; 1\}$, and 1 is assigned to stock $\mathrm{k}$ if the company participates in the United Nations GC and 0 otherwise. Hence, the maximum value that this variable can take for a client is 100 , which means that $100 \%$ of the portfolio value is invested into companies that participate in the United Nations GC. The minimum value that this variable can take for a client is 0. The MSCI ESG (Letter Coded) dependent variable of the regression shown in column 2 is defined as:

$$
M S C I E S G(\text { LetterCoded })_{i}=\sum\left(\text { Weightof stockk }(\text { in } \%) * M S C I \_E S G \_L e t t e r_{k}\right),
$$


where $M S C I \_E S G_{-}$Letter $_{k} \epsilon\left\{0 ; \frac{1}{6} ; \frac{1}{3} ; \frac{1}{2} ; \frac{2}{3} ; \frac{5}{6} ; 1\right\}$. This variable represents the quantified MSCI ESG letter rating of stock k, which corresponds to CCC, B, BB, BBB, A, AA, AAA, respectively. Similarly, MSCI ESG (Color Coded), the dependent variable of the regression shown in column 3 , is defined as:

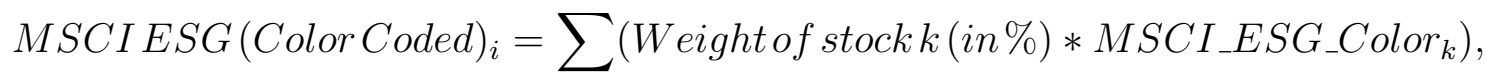

where $M S C I \_E S G \_C o l o r_{k} \epsilon\{0 ; 0.5 ; 1\}$ correspond to the MSCI ESG color ratings gray, yellow, and green, respectively. Both quantifications of the MSCI ESG scores take a value between 0 and 100, as the dependent variable in column 1. Finally, column 4 shows a regression with an average social responsibility score, defined as

$$
\text { SocialResponsibility } \text { Score }_{i}=\frac{\text { United Nations } G C_{i}+\text { MSCI ESG }(\text { Letter Coded })_{i}}{2}
$$

Table 1 shows that under all definitions of social responsibility, advisors create more socially responsible portfolios when a client gives an SRI mandate. Hence, we are confident that our treatment was administered successfully.

\subsection{SRI mandates lead to higher advisory fees}

Result 1: Financial advisors charge a higher advisory fee to clients who give an SRI mandate.

Support: We next consider whether advisors in our sample charge a different advisory fee when a client gives a mandate for SRI. The mean fee in the entire sample that is charged to clients is $\mu=1.92 \%$ ( $\mathrm{SD}=0.97 \%$ ). Figure 7 graphically shows the average mean adjusted advisory fee that is charged by investor mandate. For client i, the mean adjusted fee is the fee that is charged by advisor $\mathrm{j}$ to client $\mathrm{i}$ minus the average fee charged by advisor $\mathrm{j}$ to all four clients allocated to advisor $\mathrm{j}$. The error bars represent $+/$ - one standard error. The figure reveals a tendency for advisors to charge a higher fee when a 
Table 1: Advisors create more socially responsible portfolios for SRI clients

\begin{tabular}{lcccc}
\hline & $(1)$ & $(2)$ & $(3)$ & $(4)$ \\
Dependent & United Nations & MSCI ESG & MSCI ESG & Social Responsibility \\
Variable: & GC & (Letter Coded) & Color Coded) & Score \\
\hline SRI Mandate & $4.266^{* * *}$ & $1.388^{* * *}$ & $1.351^{* * *}$ & $2.827^{* * *}$ \\
& $(0.493)$ & $(0.179)$ & $(0.231)$ & $(0.297)$ \\
$\alpha$ & $22.970^{* * *}$ & $60.99^{* * *}$ & $25.170^{* * *}$ & $41.980^{* * *}$ \\
& $(4.584)$ & $(1.668)$ & $(2.145)$ & $(2.758)$ \\
\hline Observations & 1,380 & 1,380 & 1,380 & 1,380 \\
Adjusted $R^{2}$ & 0.59 & 0.55 & 0.50 & 0.62 \\
\hline
\end{tabular}

Notes: ${ }^{* *} p<0.05 ;{ }^{* * *} p<0.01$. Standard errors in brackets. All columns show the coefficient estimates of OLS regressions with advisor fixed effects. The dependent variables in column 1,2,3, and 4 are defined in equation 3, 4, 5, and 6, respectively. SRI Mandate is equal to 1 if a client gave a mandate for SRI and 0 otherwise.

client gives a mandate for SRI, compared to a client who gives a conventional mandate.

We formally test this using the following model;

$$
\begin{aligned}
& \text { Fee }_{i}=\alpha+\beta_{1} * \psi+\beta_{2} * \text { SRI_Mandate }{ }_{i}+\beta_{3} * \text { Female }_{i}+\beta_{4} * \text { High_Age }_{i} \\
& +\beta_{5} * \text { High_Income } i+\beta_{6} * \text { Round }_{i}+\epsilon_{i},
\end{aligned}
$$

where client i's fee is determined by: $\psi$ (A vector of advisor fixed effects), SRI_Mandate ${ }_{i}$ $\epsilon\{1$ if a client gives a mandate for SRI, 0 otherwise $\}$, Female $_{i} \epsilon\{1$ if a client is female, 0 if a client is male $\}, H_{i g h}$ Age $_{i} \epsilon$ \{ 1 if a client is between 45 and 54 years old, 0 if a client is between 35 and 44 years old $\}, H_{i g h \_I n c o m e} \epsilon\{1$ if a client has a gross annual income between $\$ 60,000$ and $\$ 79,999$, 0 if a client has a gross annual income between $\$ 40,000$ and $\$ 59,999\}$, and Round $_{i} \epsilon\{1,2,3,4\}$ controls for order effects.

Table 2 shows the results of the OLS regression. Column 1 shows the effect of a client's investment mandate on the fee charged by advisors, without including any controls. Advisors charge a higher fee of 4.9 basis points $(\mathrm{p}=0.011)$ when a client gives an SRI mandate. Column 2 shows the outcome of regression equation 7 . The estimated effect 


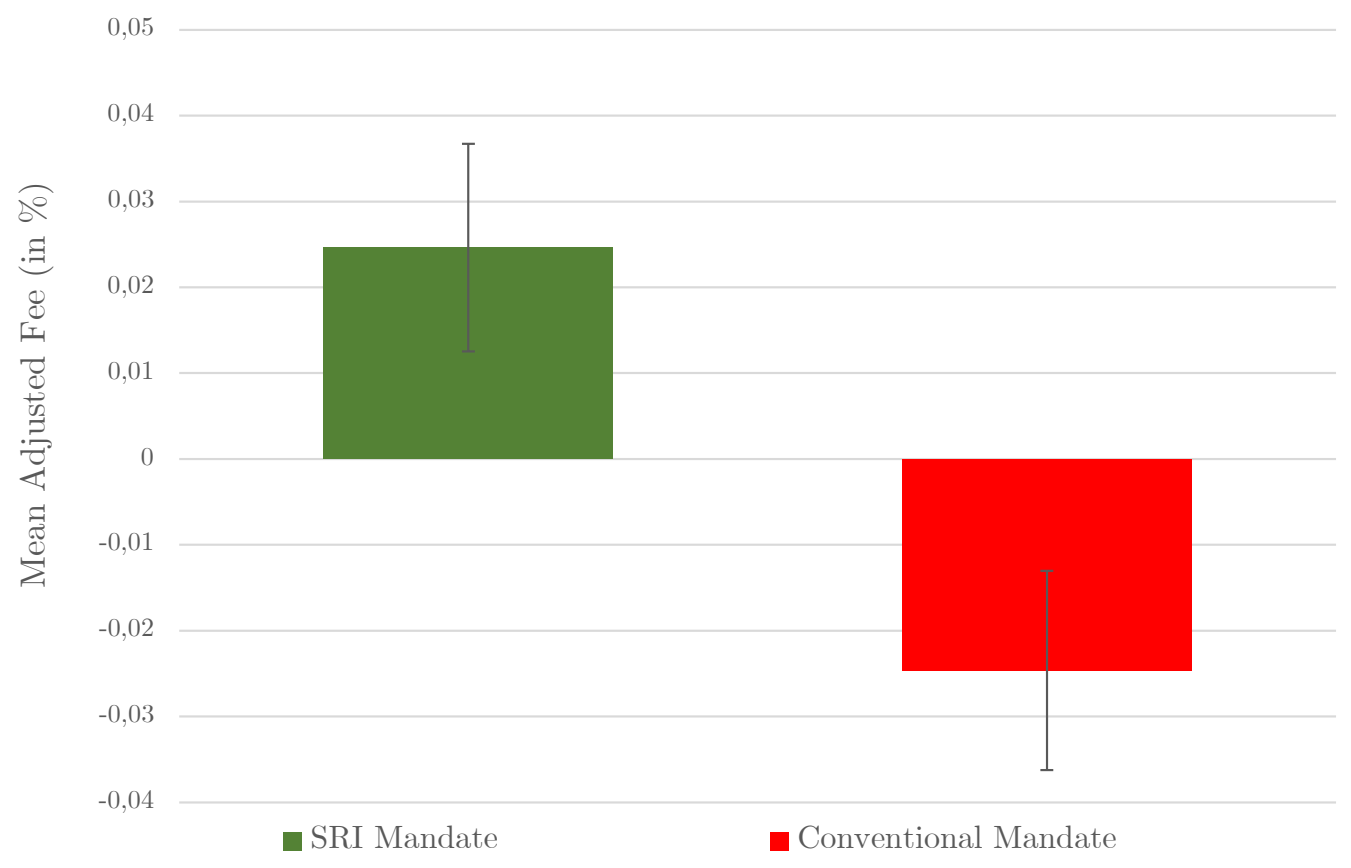

Figure 7: Average mean adjusted fee charged by investment mandate

size does not change when including all control variables. For robustness, we re-run the model in a Tobit regression. The dependent variable $F e e_{i}$ is bounded between 0 and $4 \%$, and we control for the possibility that the data are censored. The outcome of the model is shown in Table A3. The estimated effect of an SRI mandate on the charged fee increases to above 5 basis points $(\mathrm{p}=0.004)$. Further, some job types in our sample may only be indirectly involved with financial advice (account managers and customer support). In Table A5, we show that excluding these job types does not change our results.

\subsection{SRI mandates do not lead to more advisor effort}

Result 2: Financial advisors do not spend more time or exert more effort for clients who give an SRI mandate.

Support: In this section, we consider whether advisors put more time or effort into constructing portfolios on behalf of clients who give an SRI mandate. This potential extra effort could justify why advisors charge higher fees to those clients. The results 
Table 2: Advisors charge higher fees to SRI clients

$(1)$

\begin{tabular}{lcc} 
Dependent Variable: & Fee (in\%) & Fee (in\%) \\
\hline SRI Mandate & $0.049^{* *}$ & $0.049^{* *}$ \\
& $(0.019)$ & $(0.019)$ \\
Female & -0.033 \\
& & $(0.019)$ \\
High Age & 0.001 \\
& & $(0.023)$ \\
High Income & 0.014 \\
& & $(0.023)$ \\
Round & & 0.004 \\
& & $(0.009)$ \\
$\alpha$ & $1.975^{* * *}$ & $1.945^{* * *}$ \\
& $(0.180)$ & $(0.182)$ \\
\hline Observations & 1,380 & 1,380 \\
Adjusted R2 & 0.86 & 0.86 \\
\hline
\end{tabular}

Notes: ${ }^{* *} p<0.05 ;{ }^{* * *} p<0.01$. Standard errors in brackets. Column 1 and 2 show the coefficient estimates of OLS regressions. Both regressions have the fee (in percent) charged by an advisor to a client as the dependent variable. Both regressions include advisor fixed effects. SRI Mandate is equal to 1 if a client gives a mandate for SRI and 0 otherwise. Female is equal to 1 if a client is female and 0 if a client is male. High Age is equal to 1 if a client is between 45 and 54 years old, 0 if a client is between 35 and 44 years old. High Income is equal to 1 if a client has a gross annual income between $\$ 60,000$ and $\$ 79,999,0$ if a client has a gross annual income between $\$ 40,000$ and $\$ 59,999$. Round ${ }_{i} \epsilon\{1,2,3,4\}$ indicates whether a client was the first, second, third, or fourth client shown to the advisor, respectively.

are displayed in Table 3. The first two columns show the outcome of OLS regressions, with the natural logarithm of the time spent on constructing a client's portfolio as the dependent variable. In both specifications, we do not detect a difference in the time spent by advisors on clients who give a mandate for SRI and those who do not give a mandate. Columns 3 and 4 show the outcome of OLS regressions, with the natural logarithm of the number of clicks that advisors spend on constructing a client's portfolio as the dependent variable. This is our proxy for the effort that advisors put into constructing portfolios on 
behalf of clients. There is no difference in how often advisors click when a client voices a mandate for SRI versus when a client gives a conventional investment mandate. Also, no other client characteristics can explain the number of advisor clicks once we control for order effects.

Table 3: Advisors do not exert more effort for SRI clients

\begin{tabular}{lcccc}
\hline & $(1)$ & $(2)$ & $(3)$ & $(4)$ \\
Dependent Variable: & $\log (\mathrm{Time})$ & $\log (\mathrm{Clicks}+1)$ \\
\hline SRI Mandate & 0.046 & 0.059 & 0.027 & 0.034 \\
Female & $(0.051)$ & $(0.041)$ & $(0.037)$ & $(0.034)$ \\
& $0.110^{* *}$ & 0.070 & 0.063 & 0.041 \\
High Age & $(0.050)$ & $(0.041)$ & $(0.037)$ & $(0.034)$ \\
& -0.051 & -0.002 & $-0.092^{* *}$ & -0.066 \\
High Income & $(0.059)$ & $(0.048)$ & $(0.043)$ & $(0.040)$ \\
Round & 0.079 & 0.088 & 0.006 & 0.011 \\
& $(0.059)$ & $(0.048)$ & $(0.043)$ & $(0.040)$ \\
$\alpha$ & & $-0.415^{* * *}$ & & $-0.219^{* * *}$ \\
& & $(0.019)$ & & $(0.015)$ \\
& $1.413^{* * *}$ & $2.410^{* * *}$ & 0.039 & 0.565 \\
Observations & $(0.471)$ & $(0.389)$ & $(0.347)$ & $(0.319)$ \\
\hline Adjusted R2 & 1,380 & 1,380 & 1,380 & 1,380 \\
\hline
\end{tabular}

Notes: ${ }^{* *} p<0.05{ }^{* * *} p<0.01$. Standard errors in brackets. All columns show the coefficient estimates of OLS regressions with advisor fixed effects. The dependent variable in columns 1 and 2 is the logarithm of time in seconds that advisors take to create a portfolio for a client (Obtained from metadata). The dependent variable in columns 3 and 4 is the logarithm of the number of clicks $(+1)$ that advisors take to create a portfolio for a client (Obtained from metadata). One is added to the number of clicks, as it is possible to allocate a portfolio with zero clicks, in which case the default weights are applied to stocks. SRI Mandate is equal to 1 if a client gives a mandate for SRI and 0 otherwise. Female is equal to 1 if a client is female and 0 if a client is male. High Age is equal to 1 if a client is between 45 and 54 years old, 0 if a client is between 35 and 44 years old. High Income is equal to 1 if a client has a gross annual income between $\$ 60,000$ and $\$ 79,999$, 0 if a client has a gross annual income between $\$ 40,000$ and \$59,999. Round $\epsilon\{1,2,3,4\}$ indicates whether a client was the first, second, third, or fourth client shown to the advisor, respectively. 


\subsection{Client gender does not influence fees}

Several studies show that gender affects the cost and content of financial advice (Baeckström et al., 2018; Bucher-Koenen et al., 2019; Bhattacharya et al., 2020). We therefore consider whether financial advisors charge different fees depending on a client's gender. Looking at Table 2, column 2, we see that the difference in the fee charged to male and female clients is not significant at conventional levels $(\mathrm{p}=0.094)$. Moving to Table 3 we consider, whether financial advisors take more time or exert more effort to construct portfolios for clients depending on their gender. In column 1, we see an indication that advisors take more time to construct portfolios for female clients $(\mathrm{p}=0.030)$. However, when we move to column 2, we see that this effect disappears once we control for round effects ( $\mathrm{p}=$ 0.092). In columns 3 and 4 , we see that gender does not significantly influence the number of clicks $(\mathrm{p}=0.224)$. Hence, while we see a tendency for advisors to spend more time and effort on females while charging lower fees, the differences are only marginally significant.

\subsection{SRI clients are not more likely to reject advice}

An important question is whether clients who give an SRI mandate are more likely to reject advice. If this were the case, clients ultimately do not end up paying the premium. However, clients with an SRI mandate are equally likely to accept the advice as are conventional clients.

Overall, $66.83 \%$ of the clients took the advice, while the remaining $33.17 \%$ selected stocks for themselves. Table 4 shows the marginal effects of two logit regressions. Column 1 shows a regression of client SRI preference on a binary variable indicating whether the advice was taken or not without including any controls. Column 2 controls for other client characteristics, including gender, age, and income. In both model specifications, there is no significant effect of the client mandate on whether or not the advice was taken. 
Table 4: SRI clients are not more likely to reject advice

(1)

Dependent Variable

Was the Advice Taken?

SRI Mandate

0.035

0.036

$(0.296)$

Female

High Age

High Income

$\alpha$

$0.625^{* *}$

$0.666^{* *}$

$(0.201)$

$(0.313)$

\begin{tabular}{lll}
\hline Observations & 208 & 208 \\
Pseudo- $R^{2}$ & 0.00 & 0.01 \\
\hline
\end{tabular}

Notes: ${ }^{* *} p<0.05 ;{ }^{* * *} p<0.01$. Standard errors in brackets. Columns 1 and 2 show the marginal effects of logit regressions, where the dependent variable is 1 if a client took the advice and 0 otherwise. SRI Mandate is equal to 1 if a client gives a mandate for SRI and 0 otherwise. Female is equal to 1 if a client is female and 0 if a client is male. High Age is equal to 1 if a client is between 45 and 54 years old, 0 if a client is between 35 and 44 years old. High Income is equal to 1 if a client has a gross annual income between $\$ 60,000$ and $\$ 79,999,0$ if a client has a gross annual income between $\$ 40,000$ and $\$ 59,999$.

\subsection{Additional robustness checks}

In additional analyses, we exclude all advisors who take less than five minutes to complete the experiment. We further exclude advisors whose responses throughout the experiment are inconsistent. ${ }^{22}$ We refer to this sample as the REDUCED sample. Table A6 provides an overview of the characteristics of the REDUCED sample. When running our analyses with the REDUCED sample, our findings stay the same qualitatively. The effect sizes even increase. Table A7 shows that under all definitions of social responsibility, advisors

\footnotetext{
${ }^{22} \mathrm{We}$ ask the respondents twice what their main occupation is, once at the beginning of the survey and once at the end of the survey. We ask this question slightly differently in the two instances. We remove advisors who give different answers to the two questions (most advisors give very similar answers, but we were very strict with this exclusion criterion).
} 
in the REDUCED sample create more socially responsible portfolios when a client gives an SRI mandate. Again, the effect sizes increase and all effects are still significant. Table A4 shows an estimation of the regression equation 7 with the REDUCED sample. While the results remain the same qualitatively, the effect of an SRI mandate on the charged fee increases from 4.9 basis points to 6.7 basis points $(\mathrm{p}=0.011)$. Finally, Table A8 shows that in the REDUCED sample, advisors do not exert significantly more time or effort to construct portfolios for clients who give an SRI mandate. This is in line with our finding when using the full sample.

\section{Regulator survey}

\subsection{Setup and implementation}

In addition, we conducted an online survey with European regulators. The survey included a detailed description of the research study that we had run (See section B.4 for the full instructions). We then asked three sets of questions. First, we asked the regulators to predict the main outcomes of our study. Second, we asked the regulators to rate the external validity of our study. Third, we asked them whether they believe that our results require attention from policymakers and what a policy intervention would look like.

We distributed the survey to 53 regulators in Europe. The regulators in our sample include members of The European Commission's high-level expert group on sustainable finance, the Dutch Central Bank, the Authority for Financial Markets (AFM), and compliance departments of several European banks. We administered the survey to European institutions because the forthcoming regulation that will require financial advisors to ask clients whether they want to give an SRI mandate is an amendment to the European MiFID II. Table 5 shows the demographics and job descriptions of the regulators in our sample. The occupation of most of the regulators in our sample is policy work. On a five-

point likert scale, the participants rated their experience in SRI at 3.15, where 3 refers to "average." Hence, the regulators in our sample have slightly above-average experience 
with SRI-related projects and topics. The average number of years of experience in regulation is 7.83 years. The average respondent in our sample thus seems knowledgeable and relevant for the study at hand.

Table 5: Summary statistics regulators

\begin{tabular}{lcccc}
\hline & Mean & Median & SD & N \\
\hline Female & 0.43 & 0.00 & 0.50 & 53 \\
Age & 38.75 & 39.50 & 11.72 & 53 \\
Experience in SRI (5-pt Likert) & 3.15 & 3.00 & 1.25 & 53 \\
Experience in Regulation (in Years) & 7.83 & 5.00 & 8.47 & 53 \\
Policy Work & 0.23 & & & 53 \\
Research & 0.13 & & & 53 \\
Supervision & 0.11 & & & 53 \\
Analysis & 0.15 & & & 53 \\
Other & 0.36 & & & 53 \\
\hline
\end{tabular}

Notes: Female is a categorical variable (1 = female, else 0) for the gender of participants. Age was given in brackets (18-24, 25-34, 35-44, 45-54, 55-64, 65 and older), which we converted to rounded midpoints per bracket (21, 29.5, 39.5, 49.5, 59.5, 65, respectively). Experience in SRI represents the response to the question: "Compared to the average colleague in your organization, how much work experience do you have with projects/topics that are related to our experiment?" ( $1=$ "Far below average", 2 = "Somewhat below average", $3=$ "Average", 4 = "Somewhat above average", $5=$ "Far above average"). Experience in Regulation represents the answer given to the question: "How much work experience do you have related to regulation and/or policy work in general? (Please enter years of experience)." Policy Work, Research, Supervision, Analysis, and Other represent the current job of participants (multiple answers per participant are possible). 


\subsection{Results}

\subsubsection{Regulators do not predict exploitation}

We first consider whether regulators can correctly predict the direction of our results. We asked the incentivized questions: "Who do you believe financial advisors charged a higher fee to in the research study?" as well as "Who do you believe financial advisors exerted more effort for in the research study?" Panel A of Table 6 shows the results. The majority of regulators $(92 \%)$ correctly predicted that advisors charge a higher fee to clients who give a mandate for SRI. However, a significantly large majority of the regulators $(60 \%)$ also incorrectly predicted that advisors exert more effort for clients who give a mandate for SRI. That is, the prior belief of the regulators in our sample is that advisors do not exploit responsible investment preferences, as the higher fee that is charged is justified by more costly effort.

We further asked the regulators to predict fee and effort differences by gender. The results are shown in Panel $\mathrm{B}$ of Table 6. A significantly large share of the regulators predicted that advisors would charge a higher fee to female clients (53\%) and exert more effort on male clients (49\%). This shows that the prior belief of the regulators is that advisors exploit female clients by charging a higher fee while exerting less costly effort. This is not in line with our findings.

\subsubsection{Regulators believe that our results are externally valid}

Next, we consider whether the regulators believe in the external validity of our results. Upon confronting the regulators with our results, we asked, "Do you believe that the findings from our research study are informative about the behavior of financial advisors in the field?" The regulators could select an answer on a five-point scale ranging from "not informative" to "very informative." We asked this question separately for the US and the EU.

The results are shown in Figure A2 for the US and in Figure A3 for the EU. A total of $74 \%$ of respondents believe that our findings are "very informative," "informative," or "somewhat informative" about the behavior of financial advisors in the field in the 
Table 6: Predictions by mandate and gender

\begin{tabular}{lcccc}
\hline Panel A & $\begin{array}{c}\text { Higher for } \\
\text { SRI }\end{array}$ & $\begin{array}{c}\text { Higher for } \\
\text { Conventional }\end{array}$ & $\begin{array}{c}\text { No } \\
\text { Difference }\end{array}$ & $\mathrm{p}$ \\
\hline Fee & 0.92 & 0.02 & 0.06 & $0.00^{* * *}$ \\
Effort & 0.60 & 0.17 & 0.23 & $0.00^{* * *}$ \\
& & & & \\
\hline Panel B & Higher for & Higher for & No & $\mathrm{p}$ \\
& Female Clients & Male Clients & Difference & \\
\hline Fee & 0.53 & 0.23 & 0.24 & $0.01^{* *}$ \\
Effort & 0.15 & 0.49 & 0.36 & $0.00^{* * *}$ \\
\hline
\end{tabular}

Notes: The table shows the proportions of responses given to the questions: "Who do you believe financial advisors charged a higher fee to in the research study?" and "Who do you believe financial advisors exerted more effort for in the research study?," respectively. The final column shows the p-values of a $\chi^{2}$ goodness-of-fit test against the null-hypothesis that all responses were given equally frequently $\left({ }^{* *} p<0.05 ;{ }^{* * *} p<0.01\right)$.

US $\left(83 \%\right.$ in the EU). When running a $\chi^{2}$ goodness-of-fit test, we find that this share is significantly higher than the share of regulators who believe that our findings are "hardly informative" or "not informative" for both the US and the EU. This shows that a significant majority of the regulators believe in the external validity of the findings from our research study.

\subsubsection{Regulators believe that our results require attention from policy mak- ers}

We asked the regulators whether they believe that the findings from our research study require attention from regulators. Further, we asked the following open question: "What do you think would be a suitable policy intervention?" This question was only completed by the respondents who believe that our results indeed require policy intervention. The responses were categorized independently by two research assistants (RAs) into one of the following: transparency, standardized fees, consumer education, other, and not filled out. Disagreements between the RAs were resolved by the researchers. 
Table 7 shows the results. A significant majority of the regulators $(81 \%)$ believes that our results require attention from policymakers. Further, the most frequently mentioned policy intervention was transparency (30\%), followed by standardized fees (25\%) and consumer education (17\%).

Table 7: Implications

Share of Regulators

Do you think that the results from our research

study require attention from regulators?

$0.81^{* * *}$

What do you think would be a suitable policy intervention?

Transparency

Standardized Fees

Consumer Education

Other

0.21

Notes: The question "Do you think that the results from our research study require attention from regulators?" was asked with possible responses "Yes" or "No." the share of regulators refers to the proportion of regulators who selected "Yes." When running $a \chi^{2}$ goodness-of-fit test, we find that this share is significantly $(p<0.01)$ higher than the share of regulators who replied "No." The question "What do you think would be a suitable policy intervention?" was asked as an open question. The responses given by the regulators were coded independently by two research assistants (RAs). Disagreements between the two RAs were resolved by the researchers. Some regulators' responses fit into multiple categories. A total of $21 \%$ of the respondents either did not believe that our research study requires attention from regulators or did not fill out the text box.

\subsection{Results are not driven by misunderstanding}

To confirm that the results of the regulator survey were not driven by respondents being confused or lacking information, we included comprehension questions after the description of our research study. The strong majority (94\%) of the regulators answered all of the comprehension questions correctly. Further, when we exclude regulators who answered one or more of the questions incorrectly, our results remain qualitatively unchanged. 


\subsection{Results do not change when only considering SRI experts}

It could be the case that the financial regulators in our sample are not experts in SRI per se and so cannot fully judge the external validity. To rule out this possibility, we re-ran our analyses with a sub-sample. We removed regulators who answered "far below average" or "somewhat below average" to the question "Compared to the average colleague in your organization, how much work experience do you have with projects/topics that are related to our experiment?" Among this sub-sample $(\mathrm{N}=37), 94.5 \%$ consider our study to be "very informative," "informative," or "somewhat informative" for the US (84\% for the EU). In addition, $78 \%$ believe that our findings require attention from regulators. Hence, our results are robust to using a more narrow definition of "policy expert."

\section{Conclusion}

Despite the growth of SRI mandates in the market for financial advice, the impact of these mandates on consumers is not clear. This is striking, as an EU-wide amendment to the MiFID II will require financial institutions to ask clients whether they want to give an SRI mandate.

Our study shows potential unintended consequences of regulations involving SRI mandates. Specifically, it shows that financial advisors exploit clients with a socially responsible mandate by charging them higher fees that are not justified by costly effort.

Market competition is unlikely to eliminate the exploitative element observed in the experiment. First, there is evidence that the law of one price does not hold in retail financial markets. When the number of firms in the market increases, prices of homogeneous products and services do not converge to marginal costs (Carlin, 2009). This can be explained by the fact that consumers do not fully understand the complex fee structures of financial products (Barber, Odean, \& Zheng, 2005). Hence, a wide dispersion in fees prevails despite market competition (Brown \& Goolsbee, 2002; Bergstresser et al., 2008; Carlin, 2009). Second, switching financial advisors is costly to consumers, for example, as new advisors tend to restructure clients' portfolios, which leads to transaction costs 
(Gerhardt \& Hackethal, 2009).

The majority of regulators in our second survey believes that our findings require attention from policymakers. As suggested policy interventions, they mention transparency, standardization of fees, and consumer education. The extent to which these interventions are actually successful in reducing the exploitative element is an interesting question for future research studies. This question is particularly relevant, as our findings suggest that advisors' knowledge about clients' responsible investment preferences could hurt consumer welfare. 


\section{References}

Alevy, J. E., Haigh, M. S., \& List, J. A. (2007). Information cascades: Evidence from a field experiment with financial market professionals. The Journal of Finance, 62(1), 151-180.

Baeckström, Y., Silvester, J., \& Pownall, R. A. (2018). Millionaire investors: financial advisors, attribution theory and gender differences. The European Journal of Finance, 24(15), 1333-1349.

Barber, B. M., Morse, A., \& Yasuda, A. (2021). Impact investing. Journal of Financial Economics, 139(1), 162-185.

Barber, B. M., Odean, T., \& Zheng, L. (2005). Out of sight, out of mind: The effects of expenses on mutual fund flows. The Journal of Business, 78 (6), 2095-2120.

Bauer, R., Ruof, T., \& Smeets, P. (2021). Get real! individuals prefer more sustainable investments. The Review of Financial Studies, forthcoming.

Benson, K. L., \& Humphrey, J. E. (2008). Socially responsible investment funds: Investor reaction to current and past returns. Journal of Banking 8 Finance, 32(9), 18501859.

Bergstresser, D., Chalmers, J. M., \& Tufano, P. (2008). Assessing the costs and benefits of brokers in the mutual fund industry. The Review of Financial Studies, 22(10), $4129-4156$.

Bhattacharya, U., Kumar, A., Visaria, S., \& Zhao, J. (2020). Do women receive worse financial advice? Available at SSRN.

Białkowski, J., \& Starks, L. (2016). SRI funds: Investor demand, exogenous shocks and esg profiles. Working paper.

Brown, J. R., \& Goolsbee, A. (2002). Does the internet make markets more competitive? evidence from the life insurance industry. Journal of Political Economy, 110(3), $481-507$.

Bucher-Koenen, T., Hackethal, A., Koenen, J., \& Laudenbach, C. (2019). Do seemingly smarter people get better advice? Available at SSRN 2572961.

Cao, J., Titman, S., Zhan, X., \& Zhang, W. (2020). ESG preference, institutional trading, 
and stock return patterns (Tech. Rep.). National Bureau of Economic Research.

Carlin, B. I. (2009). Strategic price complexity in retail financial markets. Journal of Financial Economics, $91(3), 278-287$.

Chalmers, J., \& Reuter, J. (2020). Is conflicted investment advice better than no advice? Journal of Financial Economics.

DellaVigna, S., Pope, D., \& Vivalt, E. (2019). Predict science to improve science. Science, $366(6464), 428-429$.

Egan, M. (2019). Brokers versus retail investors: Conflicting interests and dominated products. The Journal of Finance, $74(3), 1217-1260$.

Gerhardt, R., \& Hackethal, A. (2009). The influence of financial advisors on household portfolios: A study on private investors switching to financial advice. Available at SSRN $134360 \%$.

Gibson, R., Glossner, S., Krueger, P., Matos, P., \& Steffen, T. (2020). Responsible institutional investing around the world. Swiss Finance Institute Research Paper(20-13).

Gil-Bazo, J., Ruiz-Verdú, P., \& Santos, A. A. (2010). The performance of socially responsible mutual funds: The role of fees and management companies. Journal of Business Ethics, 94(2), 243-263.

Gneezy, U., \& Imas, A. (2017). Lab in the field: Measuring preferences in the wild. In Handbook of economic field experiments (Vol. 1, pp. 439-464). Elsevier.

Hackethal, A., Haliassos, M., \& Jappelli, T. (2012). Financial advisors: A case of babysitters? Journal of Banking \& Finance, 36(2), 509-524.

Haigh, M. S., \& List, J. A. (2005). Do professional traders exhibit myopic loss aversion? an experimental analysis. The Journal of Finance, 60(1), 523-534.

Harrison, G. W., \& List, J. A. (2004). Field experiments. Journal of Economic Literature, 42(4), 1009-1055.

Hartzmark, S. M., \& Sussman, A. B. (2019). Do investors value sustainability? a natural experiment examining ranking and fund flows. The Journal of Finance, $74(6)$, $2789-2837$.

Heeb, F., Kölbel, J. F., Paetzold, F., \& Zeisberger, S. (2021). Are investors sensitive to 
impact? Available at SSRN 3765659.

Hoechle, D., Ruenzi, S., Schaub, N., \& Schmid, M. (2018). Financial advice and bank profits. The Review of Financial Studies, 31(11), 4447-4492.

Hong, H., \& Kacperczyk, M. (2009). The price of sin: The effects of social norms on markets. Journal of Financial Economics, 93(1), 15-36.

Hortaçsu, A., \& Syverson, C. (2004). Product differentiation, search costs, and competition in the mutual fund industry: A case study of s\&p 500 index funds. The Quarterly Journal of Economics, 119(2), 403-456.

Humphrey, J., Kogan, S., Sagi, J. S., \& Starks, L. T. (2020). The asymmetry in responsible investing preferences. Available at SSRN 3583862.

Karlan, D. S. (2005). Using experimental economics to measure social capital and predict financial decisions. American Economic Review, 95(5), 1688-1699.

Kaustia, M., Alho, E., \& Puttonen, V. (2008). How much does expertise reduce behavioral biases? the case of anchoring effects in stock return estimates. Financial Management, 37(3), 391-412.

Kirchler, M., Lindner, F., \& Weitzel, U. (2018). Rankings and risk-taking in the finance industry. The Journal of Finance, 73(5), 2271-2302.

Krueger, P., Sautner, Z., \& Starks, L. T. (2020). The importance of climate risks for institutional investors. The Review of Financial Studies, 33(3), 1067-1111.

Levitt, S. D., \& List, J. A. (2009). Field experiments in economics: The past, the present, and the future. European Economic Review, 53(1), 1-18.

List, J. A., \& Gallet, C. A. (2001). What experimental protocol influence disparities between actual and hypothetical stated values? Environmental and Resource Economics, 20(3), 241-254.

Pástor, L., Stambaugh, R. F., \& Taylor, L. A. (2020). Sustainable investing in equilibrium. Journal of Financial Economics.

Pedersen, L. H., Fitzgibbons, S., \& Pomorski, L. (2020). Responsible investing: The esg-efficient frontier. Journal of Financial Economics.

Raghunandan, A., \& Rajgopal, S. (2021). Do esg funds make stakeholder-friendly invest- 
ments? Available at SSRN $382635 \%$.

Riedl, A., \& Smeets, P. (2017). Why do investors hold socially responsible mutual funds? The Journal of Finance, 72(6), 2505-2550.

Roth, B., \& Voskort, A. (2014). Stereotypes and false consensus: How financial professionals predict risk preferences. Journal of Economic Behavior $\mathscr{E}$ Organization, $107,553-565$.

Shanker, H. (2019). Social preferences of investors and sustainable investing. Working paper.

USSIF. (2020). Report on us sustainable, responsible and impact investing trends. Washington, DC: US SIF.

Weitzel, U., Huber, C., Huber, J., Kirchler, M., Lindner, F., \& Rose, J. (2020). Bubbles and financial professionals. The Review of Financial Studies, 33(6), 2659-2696. 


\section{A Appendix}

Table A1: Information ranked to be most important by participants

\begin{tabular}{lcc}
\hline Information & Average Rating (1-22) & Importance Ranking \\
\hline Earnings per share (last year) & 9.38 & 1 \\
Price chart (last 5 years) & 9.71 & 2 \\
Free cash flow (last year) & 9.71 & 2 \\
Dividends (expected next year) & 9.86 & 4 \\
Industry & 10.10 & 5 \\
Price / book ratio & 10.10 & 5 \\
\hline
\end{tabular}

Table A2: Summary statistics

\begin{tabular}{lcccc}
\hline & Mean & Median & SD & N \\
\hline Age & 43.51 & 39.50 & 11.00 & 345 \\
Female & 0.45 & 0.00 & 0.50 & 345 \\
Experience & 11.16 & 10.00 & 6.42 & 345 \\
Annual Income & 110,637 & 105,000 & $54,071.53$ & 345 \\
\hline
\end{tabular}

Notes: Age was given in brackets (18-24, 25-34, 35-44, 45-54, 55-64, 65 and older), which we converted to rounded midpoints per bracket (21, 29.5, 39.5, 49.5, 59.5, 65, respectively). Female is a categorical variable $(1=$ female, else 0$)$ for the gender of participants. Experience was given in years, where "Less than 1 year" was re-coded to 1 and "More than 20 Years" was re-coded to 20. Annual Income (Gross in \$) was given in brackets (under 20,000, 20,000 - 29,999, 30,000-39,999, 40,000-49,999, 50,00059,999, 60,000-69,999, 70,000-79,999, 80,000-89,999, 90,000-99,999, 100,000— 109,999, 110,000-119,999, 120,000-129,999, 130,000-139,999, 140,000-149,999, 150,000-199,999, 200,000 or higher), which we converted to rounded midpoints per bracket (20,000; 24,999.5; 34,999.5; 44,999.5; 54,999.5; 64,999.5; 74,999.5; 84,999.5; 94,999.5; 104,999.5; 114,999.5; 124,999.5; 134,999.5; 144,999.5; 174,999.5; 200,000; respectively). 


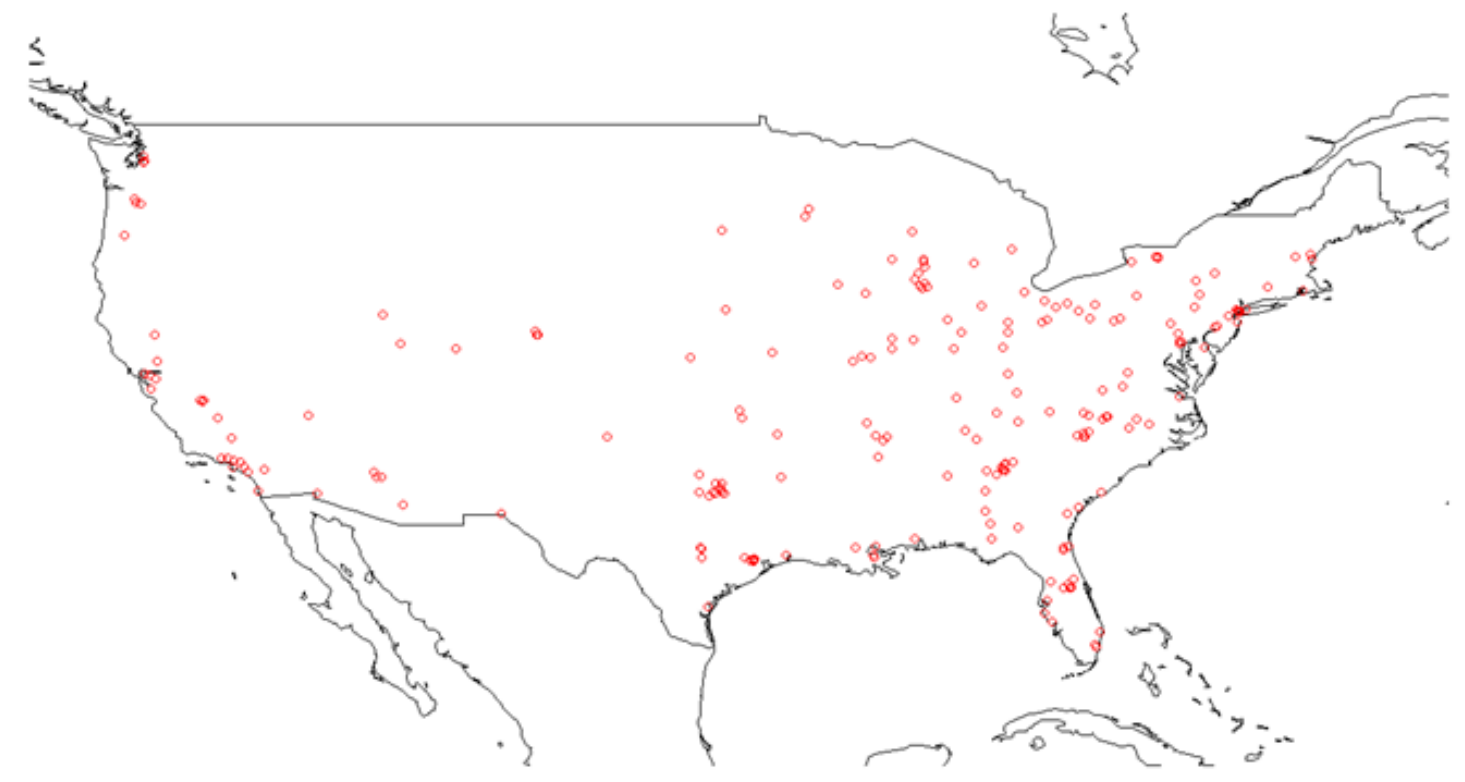

Figure A1: Location of clients

0,7

0,6

0,5

0,4

0,3

0,2

0,1

0
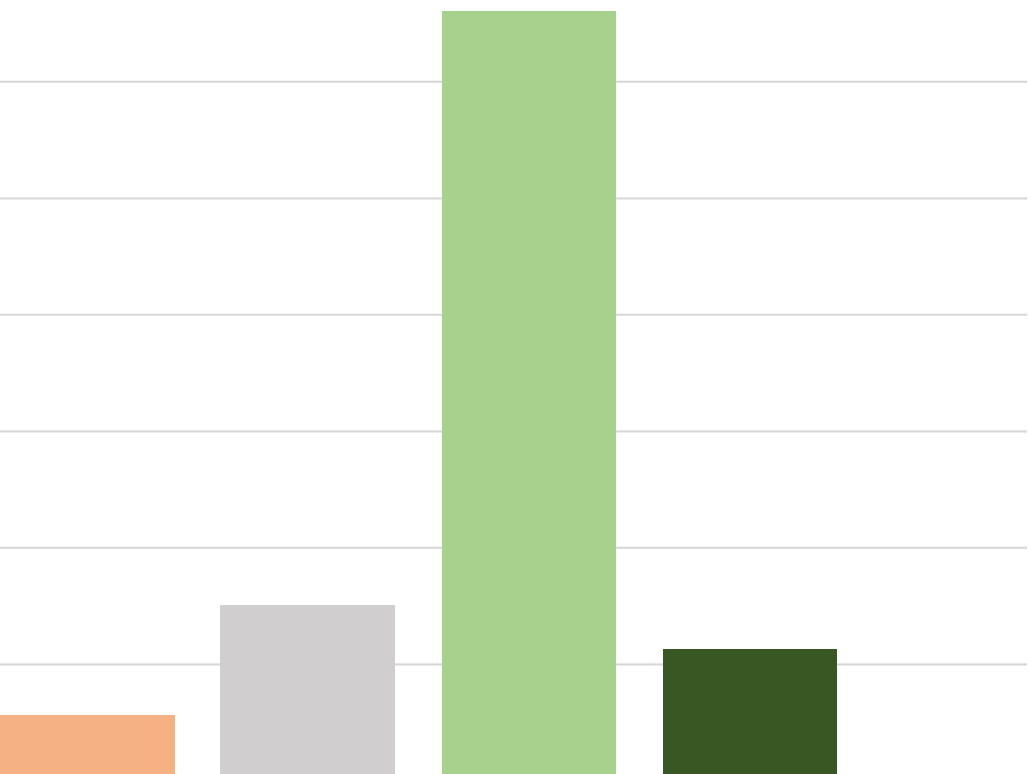

Not informative $\square$ Hardly informative $\square$ Somewhat informative $\square$ Informative $\boldsymbol{\square}$ Very Informative

Figure A2: External validity United States. Notes: Regulators' Response to the Question: "Do you believe that the findings from our research study are informative about the behavior of financial advisors in the field in the US?" 
0,7

0,6

0,5

0,4

0,3

0,2

0,1

0
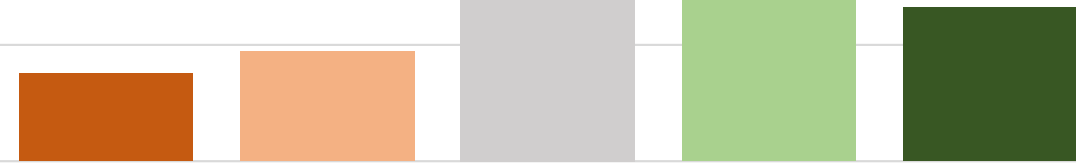

- Not informative $\square$ Hardly informative $\square$ Somewhat informative $\square$ Informative $\boldsymbol{a}$ Very Informative

Figure A3: External validity European Union. Notes: Regulators' Response to the Question: "Do you believe that the findings from our research study are informative about the behavior of financial advisors in the field in the European Union?" 
Table A3: Advisors charge higher fees to SRI clients (Tobit regression)

\begin{tabular}{|c|c|c|}
\hline & (1) & $(2)$ \\
\hline \multirow[t]{2}{*}{ SRI Mandate } & $0.051^{* * *}$ & $0.050 * * *$ \\
\hline & $(0.017)$ & $(0.017)$ \\
\hline \multirow[t]{2}{*}{ Female } & & -0.034 \\
\hline & & $(0.017)$ \\
\hline \multirow[t]{2}{*}{ High Age } & & 0.000 \\
\hline & & $(0.020)$ \\
\hline \multirow[t]{2}{*}{ High Income } & & 0.012 \\
\hline & & $(0.020)$ \\
\hline \multirow[t]{2}{*}{ Round } & & 0.005 \\
\hline & & $(0.008)$ \\
\hline \multirow[t]{2}{*}{$\alpha$} & $1.975^{* * *}$ & $1.943^{* * *}$ \\
\hline & $(0.160)$ & $(0.161)$ \\
\hline Observations & 1,380 & 1,380 \\
\hline Uncensored Observations & 1,328 & 1,328 \\
\hline Log Likelihood & -398.2 & -395.8 \\
\hline \multicolumn{3}{|c|}{$\begin{array}{l}\text { Notes: }{ }^{* *} p<0.05{ }^{* * *} p<0.01 \text {. Standard errors in brackets. Column } 1 \\
\text { and } 2 \text { show the coefficient estimates of tobit regressions. Both regres- } \\
\text { sions have the fee (in percent) charged by an advisor to a client as } \\
\text { the dependent variable. Both regressions include advisor fixed effects. } \\
\text { SRI Mandate is equal to } 1 \text { if a client gives a mandate for SRI and } 0 \\
\text { otherwise. Female is equal to } 1 \text { if a client is female and } 0 \text { if a client is } \\
\text { male. High Age is equal to } 1 \text { if a client is between } 45 \text { and } 54 \text { years old, } \\
0 \text { if a client is between } 35 \text { and } 44 \text { years old. High Income is equal to } \\
1 \text { if a client has a gross annual income between } \$ 60,000 \text { and } \$ 79,999 \text {, } \\
0 \text { if a client has a gross annual income between } \$ 40,000 \text { and } \$ 59,999 . \\
\text { Round } \epsilon\{1,2,3,4\} \text { indicates whether a client was the first, second, } \\
\text { third, or fourth client shown to the advisor, respectively. }\end{array}$} \\
\hline
\end{tabular}


Table A4: Advisors charge higher fees to SRI clients (REDUCED sample)

\begin{tabular}{lcc}
\hline & $(1)$ & $(2)$ \\
\hline SRI Mandate & $0.067^{* * *}$ & $0.065^{* *}$ \\
Female & $(0.026)$ & $(0.026)$ \\
& & -0.044 \\
High Age & $(0.026)$ \\
& & 0.018 \\
High Income & & $(0.030)$ \\
& & 0.002 \\
Round & & $(0.030)$ \\
& & 0.012 \\
$\alpha$ & $2.116^{* * *}$ & $(0.012)$ \\
& $(0.186)$ & $2.103^{* * *}$ \\
Observations & 832 & $(0.191)$ \\
Adjusted R2 & 0.86 & 832 \\
\hline
\end{tabular}

Notes: ${ }^{* *} p<0.05 ;{ }^{* * *} p<0.01$. Standard errors in brackets. Column 1 and 2 show the coefficient estimates of OLS regressions. Both regressions have the fee (in percent) charged by an advisor to a client as dependent variable. Both regressions include advisor fixed effects. SRI Mandate is equal to 1 if a client gives a mandate for SRI and 0 otherwise. Female is equal to 1 if a client is female and 0 if a client is male. High Age is equal to 1 if a client is between 45 and 54 years old, 0 if a client is between 35 and 44 years old. High Income is equal to 1 if a client has a gross annual income between $\$ 60,000$ and $\$ 79,999$, 0 if a client has a gross annual income between \$40,000 and \$59,999. Round $_{i} \in\{1,2,3,4\}$ indicates whether a client was the first, second, third, or fourth client shown to the advisor, respectively. 
Table A5: The main effect is not driven by customer support or account managers

(1)

(2)

Customer Support Account Manager

\begin{tabular}{lcc} 
& Removed & Removed \\
\hline SRI Mandate & $0.045^{* *}$ & $0.043^{* *}$ \\
Female & $(0.021)$ & $(0.020)$ \\
& -0.032 & -0.036 \\
High Age & $(0.021)$ & $(0.020)$ \\
& 0.023 & 0.027 \\
High Income & $(0.024)$ & $(0.024)$ \\
& 0.000 & 0.022 \\
Round & $(0.024)$ & $(0.024)$ \\
& 0.006 & 0.004 \\
$\alpha$ & $(0.009)$ & $(0.009)$ \\
& $1.979^{* * *}$ & $1.975^{* * *}$ \\
\hline Observations & $(0.182)$ & $(0.176)$ \\
Adjusted R2 & 1,172 & 1,196 \\
\hline
\end{tabular}

Notes: ${ }^{* *} p<0.05 ;{ }^{* *} p<0.01$. Standard errors in brackets. Both regressions have the fee (in percent) charged by an advisor to a client as dependent variable. Both regressions include advisor fixed effects. SRI Mandate is equal to 1 if a client gives a mandate for SRI and 0 otherwise. Female is equal to 1 if a client is female and 0 if a client is male. High Age is equal to 1 if a client is between 45 and 54 years old, 0 if a client is between 35 and 44 years old. High Income is equal to 1 if a client has a gross annual income between $\$ 60,000$ and \$79,999, 0 if a client has a gross annual income between \$40,000 and \$59,999. Round $_{i} \epsilon\{1,2,3,4\}$ indicates whether a client was the first, second, third, or fourth client shown to the advisor, respectively. 
Table A6: Summary statistics (REDUCED sample)

\begin{tabular}{lcccc}
\hline & Mean & Median & SD & N \\
\hline Age & 43.20 & 39.50 & 11.38 & 208 \\
Female & 0.49 & 0.00 & 0.50 & 208 \\
Experience & 10.69 & 10.00 & 6.40 & 208 \\
Annual Income & 108,028 & 100,000 & $56,294.35$ & 208 \\
\hline
\end{tabular}

Notes: Age was given in brackets (18-24, 25-34, 35-44, 45-54, 55-64, 65 and older), which we converted to rounded midpoints per bracket (21, 29.5, 39.5, 49.5, 59.5, 65, respectively). Female is a categorical variable $(1=$ female, else 0$)$ for the gender of participants. Experience was given in years, where "Less than 1 year" was re-coded to 1 and "More than 20 Years" was re-coded to 20. Annual Income (Gross in \$) was given in brackets (under 20,000, 20,000-29,999, 30,00039,999, 40,000-49,999, 50,000-59,999, 60,000-69,999, 70,000-79,999, 80,000-89,999, 90,000-99,999, 100,000-109,999, 110,000-119,999, 120,000-129,999, 130,000-139,999, 140,000-149,999, 150,000-199,999, 200,000 or higher), which we converted to rounded midpoints per bracket (20,000; 24,999.5; 34,999.5; 44,999.5; 54,999.5; 64,999.5; $74,999.5 ; 84,999.5 ; 94,999.5 ; 104,999.5 ; 114,999.5 ; 124,999.5 ; 134,999.5 ; 144,999.5$; 174,999.5; 200,000; respectively).

Table A7: Advisors create more socially responsible portfolios for SRI clients (REDUCED sample)

\begin{tabular}{lcccc}
\hline & $(1)$ & $(2)$ & $(3)$ & $(4)$ \\
& United Nations & MSCI & MSCI & Social Responsibility \\
& Global Compact & (Letter Coded) & (Color Coded) & Score \\
\hline SRI Mandate & $5.148^{* * *}$ & $1.497^{* * *}$ & $1.587^{* * *}$ & $3.322^{* * *}$ \\
& $(0.646)$ & $(0.250)$ & $(0.317)$ & $(0.391)$ \\
$\alpha$ & $23.676^{* * *}$ & $61.152^{* * *}$ & $25.619^{* * *}$ & $41.980^{* * *}$ \\
& $(4.671)$ & $(1.808)$ & $(2.292)$ & -2.758 \\
\hline Observations & 832 & 832 & 832 & 832 \\
Adjusted R2 & 0.63 & 0.56 & 0.52 & 0.62 \\
\hline
\end{tabular}

Notes: ${ }^{* *} p<0.05 ;{ }^{* * *} p<0.01$. Standard errors in brackets. All columns show the coefficient estimates of OLS regressions with advisor fixed effects. The dependent variables in column 1,2,3, and 4 are defined in equation 3, 4, 5, and 6, respectively. SRI Mandate is equal to 1 if a client gave a mandate for SRI and 0 otherwise. 
Table A8: Advisors do not exert more effort for SRI clients (REDUCED sample)

\begin{tabular}{lcccc}
\hline & $(1)$ & $(2)$ & $(3)$ & $(4)$ \\
Dependent Variable & $\log (\mathrm{Time})$ & $\log (\mathrm{Clicks}+1)$ \\
\hline SRI Mandate & 0.063 & 0.098 & 0.002 & 0.020 \\
Female & $(0.069)$ & $(0.057)$ & $(0.050)$ & $(0.046)$ \\
& 0.116 & 0.060 & 0.089 & 0.060 \\
High Age & $(0.069)$ & $(0.057)$ & $(0.050)$ & $(0.046)$ \\
& -0.067 & $-0,010$ & $-0.135^{* *}$ & $-0.105^{* *}$ \\
High Income & $(0.080)$ & $(0.066)$ & $(0.058)$ & $(0.053)$ \\
Round & 0.076 & 0.095 & 0.026 & 0.036 \\
& $(0.080)$ & $(0.065)$ & $(0.058)$ & $(0.053)$ \\
$\alpha$ & & $-0.444^{* * *}$ & & $-0.230^{* * *}$ \\
& & $(0.025)$ & & $(0.020)$ \\
\hline Observations & $4.338^{* * *}$ & $5.426^{* * *}$ & $3.446^{* * *}$ & $4.011^{* * *}$ \\
Adjusted R2 & $(0.506)$ & $(0.419)$ & $(0.367)$ & $(0.339)$ \\
\hline
\end{tabular}

Notes: ${ }^{* *} p<0.05{ }^{* * *} p<0.01$. Standard errors in brackets. All columns show the coefficient estimates of OLS regressions with advisor fixed effects. The dependent variable in columns 1 and 2 is the logarithm of time in seconds that advisors take to create a portfolio for a client (Obtained from metadata). The dependent variable in columns 3 and 4 is the logarithm of the number of clicks (+1) that advisors take to create a portfolio for a client (Obtained from metadata). One is added to the number of clicks, as it is possible to allocate a portfolio with zero clicks, in which case the default weights are applied to stocks. SRI Mandate is equal to 1 if a client gives a mandate for SRI and 0 otherwise. Female is equal to 1 if a client is female and 0 if a client is male. High Age is equal to 1 if a client is between 45 and 54 years old, 0 if a client is between 35 and 44 years old. High Income is equal to 1 if a client has a gross annual income between $\$ 60,000$ and $\$ 79,999,0$ if a client has a gross annual income between $\$ 40,000$ and \$59,999. Round . $_{i}\{1,2,3,4\}$ indicates whether a client was the first, second, third, or fourth client shown to the advisor, respectively. 
B Online appendix

B.1 Instructions advisors

B.2 Instructions clients

B.3 Instructions selection

B.4 Instructions regulators 


\section{Instructions Advisors}

\section{Start of Block: Welcome}

\section{Welcome}

- Thank you for participating in the survey. Participation will take less than 15 minutes.

- Upon full completion of the survey, you will receive a completion fee of $\$ 2$.

- In addition, depending on the decisions that you and other survey participants make, you can earn up to $\$ 45$.

- All earnings will be paid out in points that correspond to the dollar value indicated in this study.

- We will depersonalize all data and will only use them for scientific purposes.

This study adheres to the principles of economic experiments: participants are not deceived and earnings are paid out for real.

- Marten Laudi (Maastricht University)

- Prof. Dr. Paul Smeets (Maastricht University)

- Prof. Dr. Utz Weitzel (VU Amsterdam, Radboud University)

${ }^{\star \star *}$ Please click below to start. ${ }^{* * *}$ 


\section{Informed Consent}

- Before you decide whether or not take part in the study, we will give you some information. Please take time to read the information carefully.

- What does my participation involve? Participation involves you filling out the following survey, which will take around 15 Minutes. Participation is voluntary. You can decide to quit the survey at any moment.

- What happens to the data collected in this survey? We will depersonalize all data and will only use them for scientific purposes. The anonymized research data is accessible to other scientists for a period of at least 10 years. The data cannot be traced back to you.

- Ethical assessment This research study has been approved by the Maastricht University Ethical Review Commitee Inner City Faculties (ERCIC).

- More information? Should you want more information on this research study, please contactm.laudi@maastrichtuniversity.nl

I agree

I do not agree

\section{End of Block: Informed Consent}

\section{Start of Block: Screener Finance}

Which industry sector are you working in?

Agriculture, forestry \& fishing (4) ... Transport (20) 
Which of the following best describes your current job? (Please select a maximum of 2)

account manager

accounting/controlling

analysis/research/valuation

area manager

asset liability mgmt

compliance

consulting in management

consulting in processes

corporate finance

acquisitions

client advisor

customer support

fund management

fund placement

general mgmt/admin

investment advisor

investment banking 
IT-support/mgmt

planning, financial

portfolio management

private equity/banking

product manager

project developer

regulation, financial

relationship manager

risk management

sales

supervision, financial

trading/brokerage

treasury

wealth management

other: 
Please provide a brief description of the main tasks in your job.

\section{End of Block: Job Function Description}

\section{Start of Block: Instructions 1}

\section{Instructions (1/3)}

- Please read the following instructions carefully. We will ask you to answer two questions about them afterwards.

- You have two chances to answer the comprehension questions correctly.

- If you fail to do so, you will not be able to complete the survey and you will not receive the completion fee of $\$ 2$.

- In the following, you will select a portfolio of stocks on behalf of a client.

- This client is a real person, a US citizen, who is not a financial professional.

- The portfolio has a starting value of $\$ 1,000$.

- For selecting stocks on behalf of your client, you can determine an advisory fee.

\section{Your client has two options:}

- Take your advice: Your client will pay the advisory fee to you and will see the stock portfolio that you selected in return.

- Not to take your advice: Your client will not pay the advisory fee to you and will not see the portfolio that you selected. The client will then select a portfolio of stocks for him/herself. 


\section{Instructions (2/3)}

\section{Payment to your client:}

- Your client's payment is based on the return of the portfolio over the coming 12 months.

- If they choose your portfolio, the fee you receive will be deducted from this payment.

- Your client will be paid out 12 months after the survey is completed.

- Every 10th client (randomly drawn) will be paid.

\section{Payment to you:}

- If your client decides to see the portfolio you created, you receive the advisory fee that you set.

- If your client decides not to see the portfolio you created, you receive no additional payment.

- You will be paid within two weeks after the survey is completed.

- Example 1: You set an advisory fee of $\$ \mathrm{e}\{$ round( e://Field/Instr_Fee ,1 ) \}\%. Your client invests in your portfolio. You will be paid $\$ 1,000 * \$ e\{$ round( e://Field $/ /$ nnstr_Fee , 1 ) $\} \%=$ $\$ \$$ e $\{$ round( e://Field/Instr_Fee , 1 ) * 10\}.

- Example 2: You set an advisory fee of $\$$ e\{ round( e://Field/Instr_Fee ,1 ) \}\%. Your client does not invest in your portfolio. You will be paid $\$ 0$.

\section{End of Block: Instructions 2}

\section{Start of Block: Instructions 3}

\section{Instructions (3/3)}

- In total, you will create 4 different portfolios for $\mathbf{4}$ clients.

- You will set a fee for each of these 4 clients.

- 1 out of your 4 clients (randomly selected) will be able to invest in the portfolio that you created for them.

- The fee of this selected portfolio will then be relevant for your payment.

- The selected portfolio will be bought in real life for every 10 th client.

- Proof of stock transactions and earnings calculations will be communicated by the research team to you and the client (using depersonalized data). This is to ensure that all information above is transparent and credible.

\section{End of Block: Instructions 3}




\section{Comprehension Quiz}

You have two chances to answer both comprehension questions correctly.

If you fail to do so, you will not be able to complete the survey and you will not receive the completion fee of $\$ 2$.

What is not a possible investment for your clients?

A stock portfolio that they select themselves

The stock portfolio that you select on their behalf

A money market investment

Consider the following scenario. You set an advisory fee of $\$$ e $\{$ round( e://Field/Quiz_Fee ,1 ) \}\%. Your client decides to take your portfolio advice. How much will you be paid?

$\$ 0$

$\$ \$$ e $\{$ round( e://Field/Quiz_Fee , 1 ) $\}$

$\$ \$ \mathrm{e}\left\{\operatorname{round}(\mathrm{e}: / /\right.$ Field/Quiz_Fee, 1$\left.){ }^{*} 10\right\}$

\section{End of Block: Comprehension Questions}

\section{Start of Block: Message wrong answers}

Wrong Answer (Only shown if there was a mistake in the comprehension questions)

At least one of your answers was not correct. Do you want to see the instructions again or would you like to retry answering?

See the instructions

Answer again 
Start of Block: Message wrong answers 2

Wrong Answer (Only shown if there was a mistake in the comprehension questions twice $\rightarrow$ End of Survey)

At least one of the answers you gave was not correct.

\section{End of Block: Message wrong answers 2}

\section{Start of Block: Client Allocations}

[Advisors allocated stock portfolios and set fees on behalf of four different clients. Here, one example is shown]

Client 1 out of 4

Please select a portfolio for a client with the following profile:

- Gender: Female

- Age: 35 - 44 years old

- Gross Income: $\$ 60,000$ - $\$ 79,999$ per year

- Risk Profile:

- Conservative

- Moderate

Aggressive

- Investor Mandate: More Info

- Conventional

- Socially Responsible
Client questionnaire Info

We ask clients whether they want to give you, the advisor, a mandate for socially responsible investing. We tell clients that you have access to 
- Please select your client's portfolio by weighting the 30 stocks of the Dow Jones below (To increase the

weight on one stock, first reduce the weight of another stock)

- The maximum weight per stock is $25 \%$, so the portfolio must include at least 4 stocks.

- Per default, the weights are set as in the Dow Jones Industrial Average.

- Click on a stock's name for more financial information.

- Next to each company name, you see two indicators of social responsibility:

MSCI ESG Score (O means laggard; means average; means leader) More Infó

Whether the company pledged to follow the principles of the UN Global Compact ( $\mathbf{Y}$ if $\mathbf{y e s}, \mathbf{N}$ if $\mathbf{n o}$ )

$\mathrm{MSCl}$ ESG rate companies on a 'AAA to CCC' scale according to their exposure to Environmental, Social, and

Governance risks and how well they manage those risks relative to peers. More Info

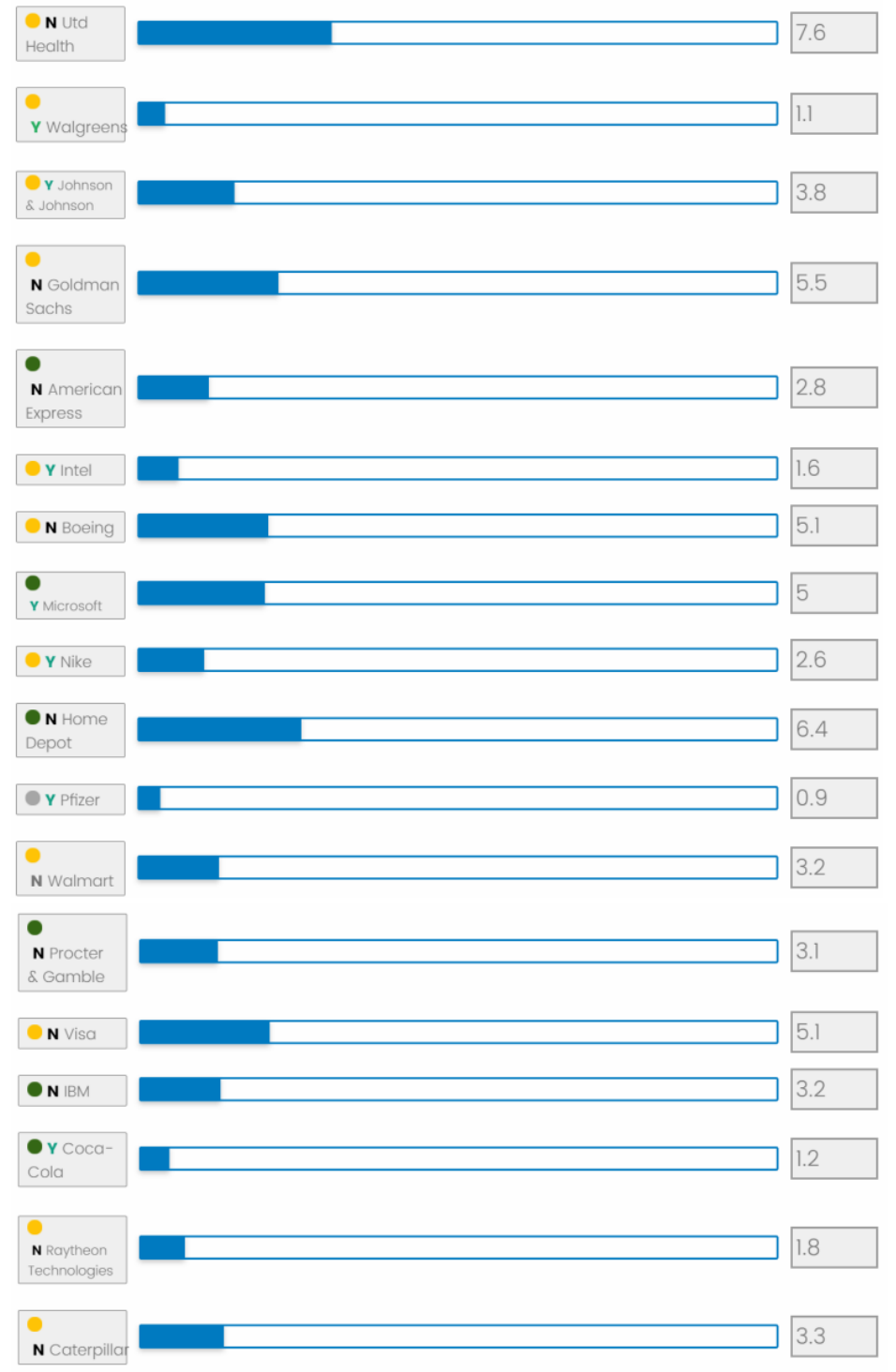

Participation in the UN Global Compact requires a commitment from a company's chief executive with support from the Board. responsibilities in four areas: human rights, labour,

environment and anti-corruption. All participants are required to produce an annual communication on progress that outlines a company's efforts to operate responsibly and support society. 


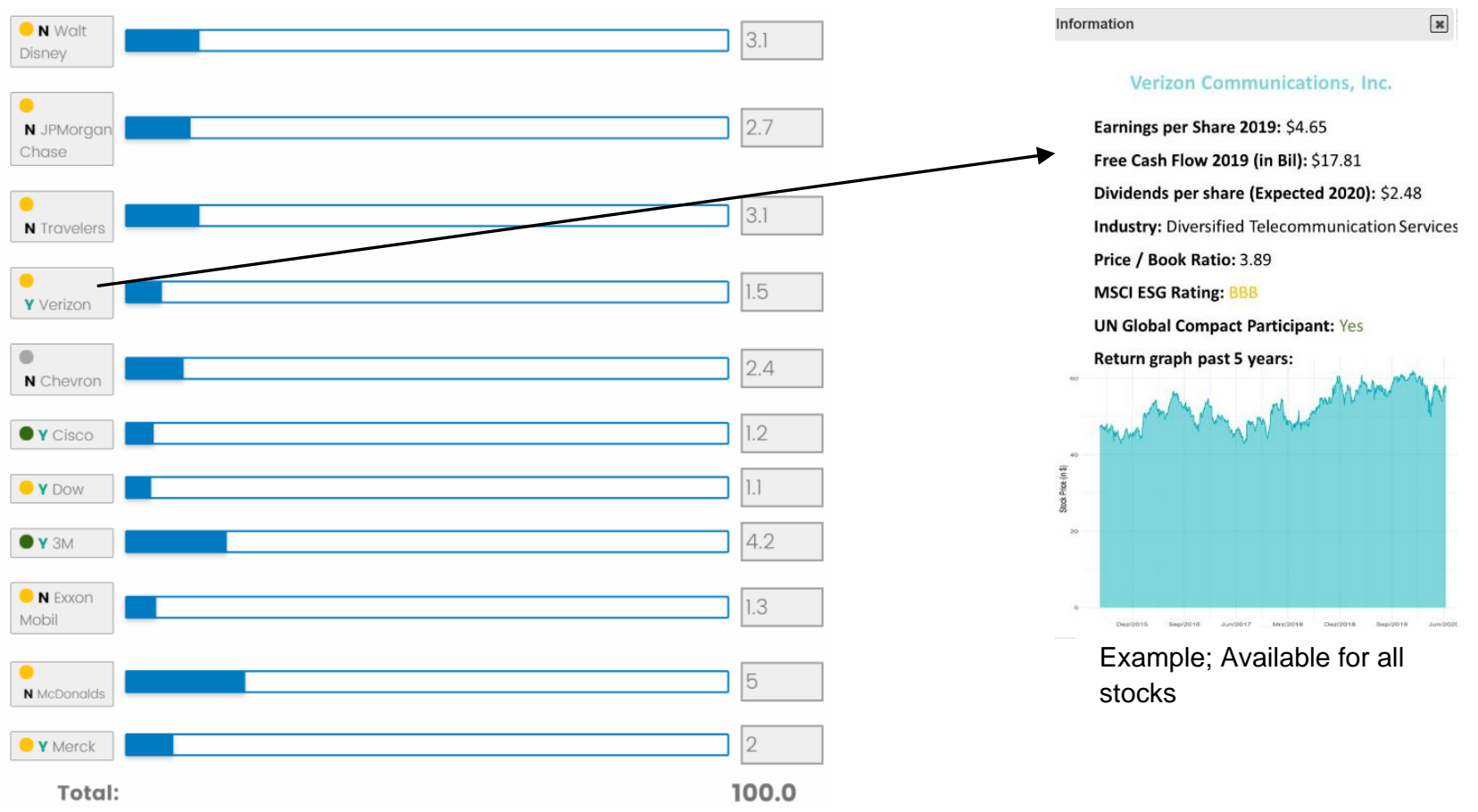

\section{Client 1 out of 4}

Please select a portfolio for a client with the following profile:

- Gender: Female

- Age: 35 - 44 years old

- Gross Income: $\$ 60,000$ - $\$ 79,999$ per year

- Risk Profile:

- Conservative

- Moderate

Aggressive

- Investor Mandate: More Info

- Conventional

- Socially Responsible 
Advisory fee for your client as a percentage of the $\$ \mathbf{1 , 0 0 0}$ portfolio value: Based on this fee,

your client will decide whether to see your advice or to make her own investment.

End of Block: Client Allocations

\section{Start of Block: Instructions client perceptions}

\section{About Your Clients}

- In the following, please answer a few questions about the four different clients.

- We also ask these questions to the clients.

- We will randomly select one of the questions that you answered about one client.

- If your answer matches the answer given by the client, you get an additional $\$ 5$.

\section{End of Block: Instructions client perceptions}

\section{Start of Block: Client Perceptions}

Client 1 out of 4

Please select a portfolio for a client with the following profile:

- Gender: Female

- Age: $35-44$ years old

- Gross Income: $\$ 60,000$ - $\$ 79,999$ per year

- Risk Profile:

- Conservative

$\circ$ Moderate

$\circ$ Aggressive

- Investor Mandate: More Info

$\circ$ Conventional

- Socially Responsible 
How willing is your client to give to good causes without expecting anything in return?

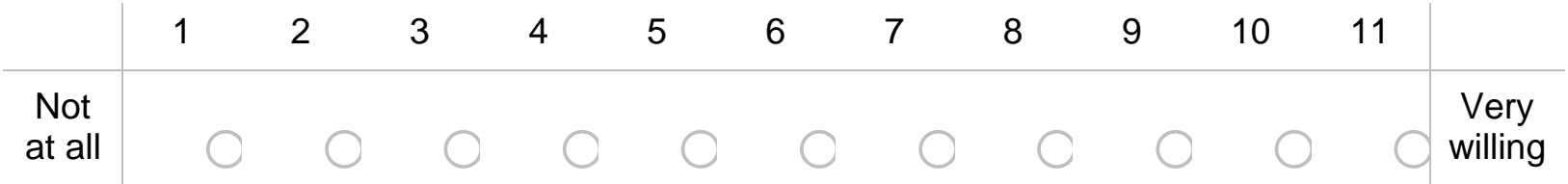

How knowledgeable do you think your client is in financial matters?
1
2
3
4
5
6
7

Not at all

knowledgeable

How much does your client enjoy to take investment decisions?

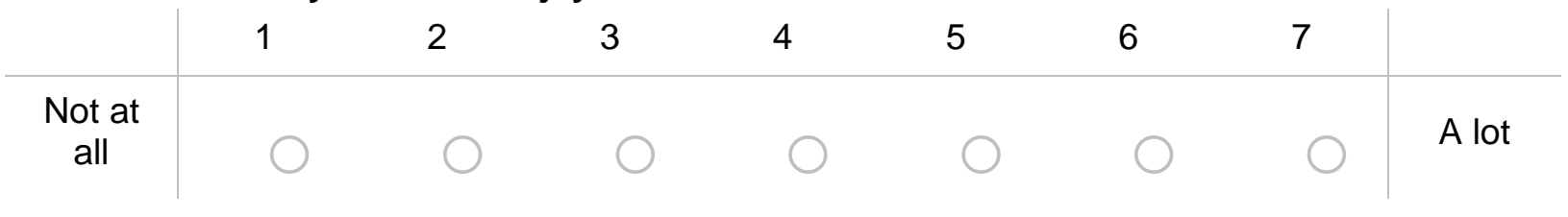

How much investment experience does your client have?

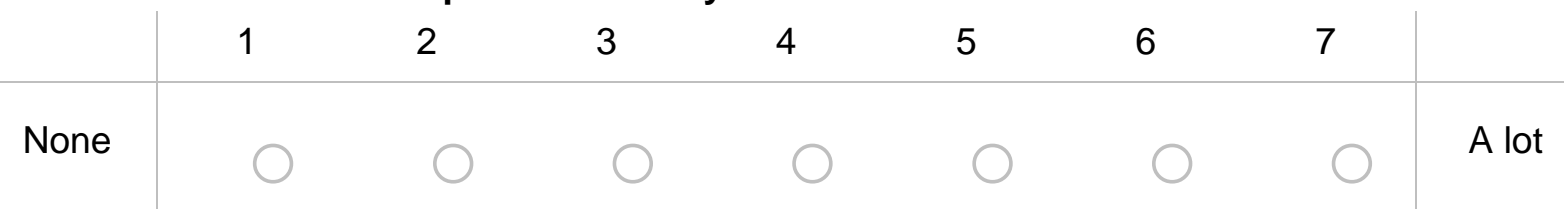

What yearly gross return does your client expect to make on the selected portfolio? (In \%)

Less than -15 ... More than 15 
Finally, last screen with questions:

What is your gender?

Male

Female

Other

What is your age?

18 - 24 years old ... 65 and older

What is the highest level of school you have completed or the highest degree you have received?

Less than high school degree ... Professional degree (JD, MD) 
Which industry sector are you working in?

Agriculture, forestry \& fishing

Automotive/Aerospace

Business \& other services

Communications (e.g. Telecommunications and Postal services)

Construction

Distribution (wholesale \& retail trade)

Education

Financial services (e.g. Banks and Insurance companies)

Health and Social work

Hotels \& Catering

IT services

Manufacture of chemical products

Manufacture of food products

Manufacturing (other)

Mining \& Utilities (e.g. Energy companies)

Public administration

Transport 
Which of the following best describes your current job?

$\boldsymbol{\nabla}$ account manager ... other:

What was your gross annual household income last year?

$\boldsymbol{\nabla}$ under $\$ 20,000 \ldots 200,000$ or more 


\section{Display This Question: \\ If Which industry sector are you working in? = Financial services (e.g. Banks and Insurance companies)}

At which type of financial institution are you currently employed? (multiple answers possible)

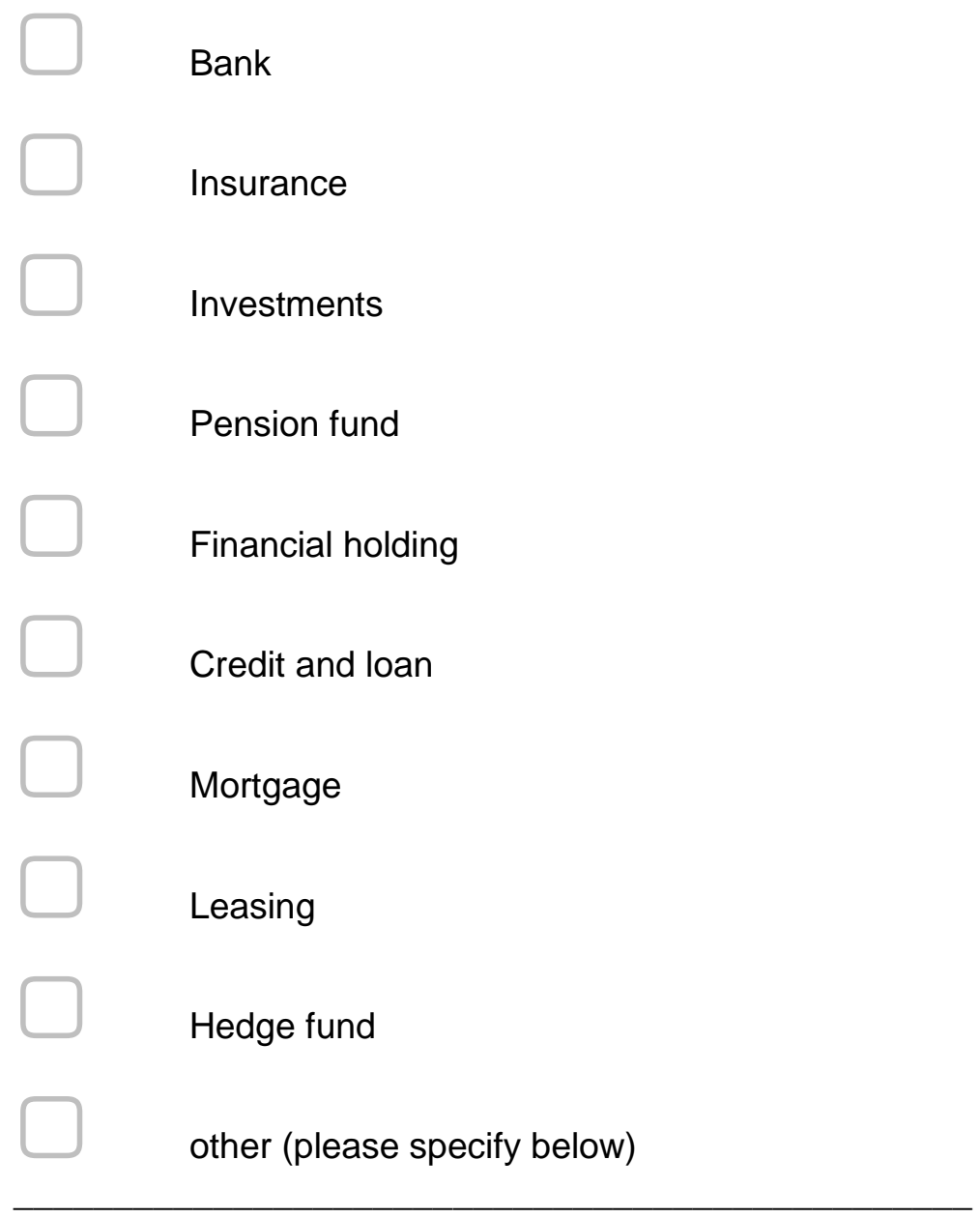

In which state do you currently reside?

Alabama ... I do not reside in the United States 
In general, how would you describe your own political viewpoint?

Very conservative ... Not sure

How willing are you to give to good causes without expecting anything in return?

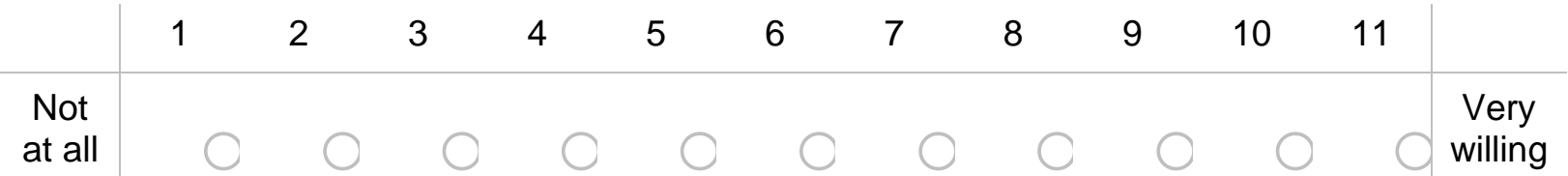

How many years of experience do you have in the financial sector?

$\boldsymbol{\nabla}$ Less than 1 ... More than 20

How would you rate your willingness to take risks...

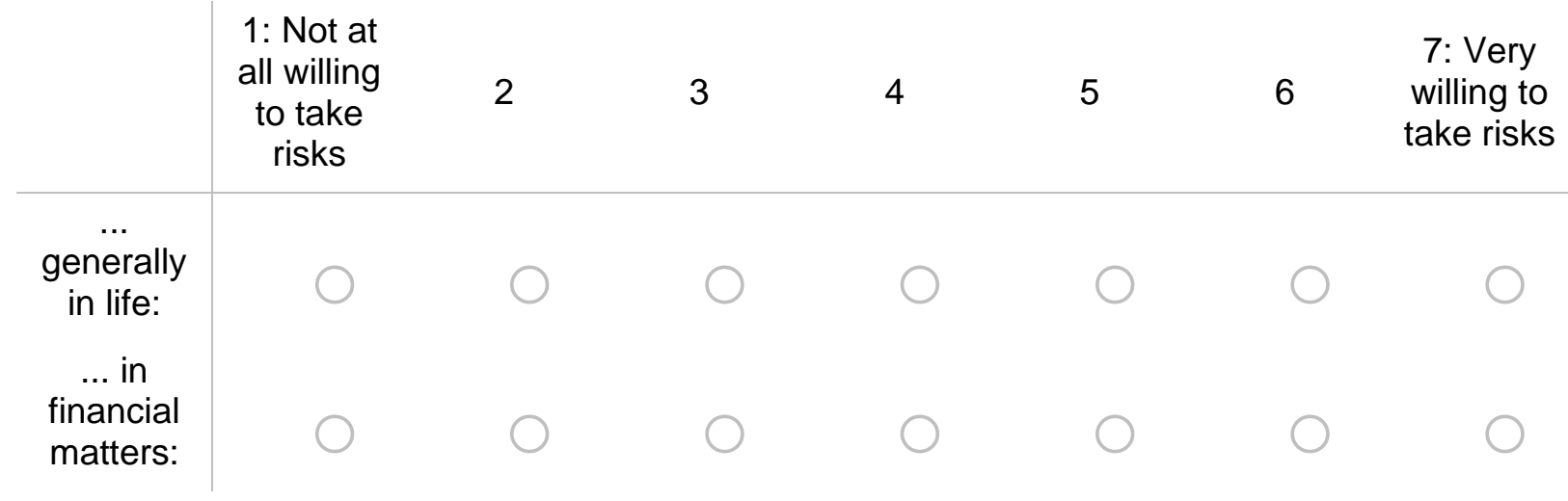

End of Block: Exit Survey

Start of Block: PLEASE VISIT URL

In about 3 weeks, you will be able to see proof of all stock transactions that we undertook to implement the portfolios. All data will be aggregated and anonymized, so that it is impossible to trace back any decision taken in the survey. 
The information will be posted on this web page:

https://feedback001.wordpress.com/

Please write down the address of the web page if you want to visit it in $\mathbf{3}$ weeks.

Thank you very much for participating.

${ }^{\star * *}$ Please click below to complete the survey *** 


\section{Instructions Clients}

\section{Start of Block: Welcome}

\section{Welcome}

- Thank you for participating in the survey. Participation will take less than 10 minutes.

- Upon full completion of the survey, you will receive a completion fee of $\$ 2$.

- In addition, you can earn up to $\$ 150$ and more, depending on your decisions in the survey and a random draw.

- All earnings will be paid out in points that correspond to the dollar value indicated in this study.

- We will depersonalize all data and will only use them for scientific purposes.

This study adheres to the principles of economic experiments: participants are not deceived and earnings are paid out for real.

- Marten Laudi (Maastricht University)

- Prof. Dr. Paul Smeets (Maastricht University)

- Prof. Dr. Utz Weitzel (VU Amsterdam, Radboud University)

${ }^{* * *}$ Please click below to start. ${ }^{* * *}$ 


\section{Informed Consent}

- Before you decide whether or not to take part in the study, we will give you some information. Please take time to read the information carefully.

- What does my participation involve? Participation involves you filling out the following survey, which will take around 10 minutes. Participation is voluntary. You can decide to quit the survey at any moment.

- What happens to the data collected in this survey? We will depersonalize all data and will only use them for scientific purposes. The anonymized research data is accessible to other scientists for a period of at least 10 years. The data cannot be traced back to you.

- Ethical assessment This research study has been approved by the Maastricht University Ethical Review Commitee Inner City Faculties (ERCIC).

- More information? Should you want more information on this research study, please contact m.laudi@maastrichtuniversity.nl

I agree

I do not agree

\section{End of Block: Informed Consent}

\section{Start of Block: Screener}

What is your gender?

Male

Female

Other

\section{What is your age?}

18 - 24 years old ... 65 and older 
What was your gross combined, annual household income last year?

under $\$ 20,000 \ldots 200,000$ or more

\section{Which industry sector are you working in?}

Agriculture, forestry \& fishing ... Transport

\section{End of Block: Screener}

\section{Start of Block: Instructions 1}

\section{Instructions (1/3): Your task}

- In this survey, you can choose a portfolio of stocks.

- You can select the stocks yourself or let a financial professional do this for you.

- For one out of ten participants in this survey, randomly selected, the selected stocks will be purchased in real life.

- We, the researchers conducting this study, will invest $\$ 1,000$ on behalf of each randomly selected participant.

- All randomly selected participants will be paid in one year, according to the return of the selected stock portfolio.

- On the following screen, we will explain how earnings are calculated for each randomly selected participant.

- Proof of stock transactions and earnings calculations will be communicated by the research team to the participants (using depersonalized data) after the stocks are bought and sold. This is to ensure that all information above is transparent and credible.

Do you want to see a preview of the stock selection screen? Depending on your decision later in the survey, either you or a financial professional (for you) will use such a screen to select a portfolio of stocks.

Yes

No 


\section{Display This Question: \\ If Do you want to see a preview of the stock selection screen? Depending on your decision later in $t$... $=$ Yes}

\section{Stock selection (IIlustration, not the actual decision screen)}

- Please select your portfolio by weighting the 30 stocks of the Dow Jones below (To increase the weight on one stock, first reduce the weight of another stock).

- The maximum weight per stock is $25 \%$, so the portfolio must include at least 4 stocks.

- Per default, the weights are set as in the Dow Jones Industrial Average.

MSCI ESG Score

$\mathbf{x}$

$\mathrm{MSCl}$ ESG rate companies on a 'AAA to CCC' scale according to their exposure to Environmental, Social, and Governance risks and how well they manage those risks relative to peers.

- Click on a stock's name for more financial information.

- Next to each company name, you see two indicators of social responsibility:

MSCI ESG Score (O means laggard; means average; means leader) More Info

Whether the company pledged to follow the principles of the UN Global Compact ( $\mathbf{Y}$ if yes, $\mathbf{N}$ if $\mathbf{n o}$ )

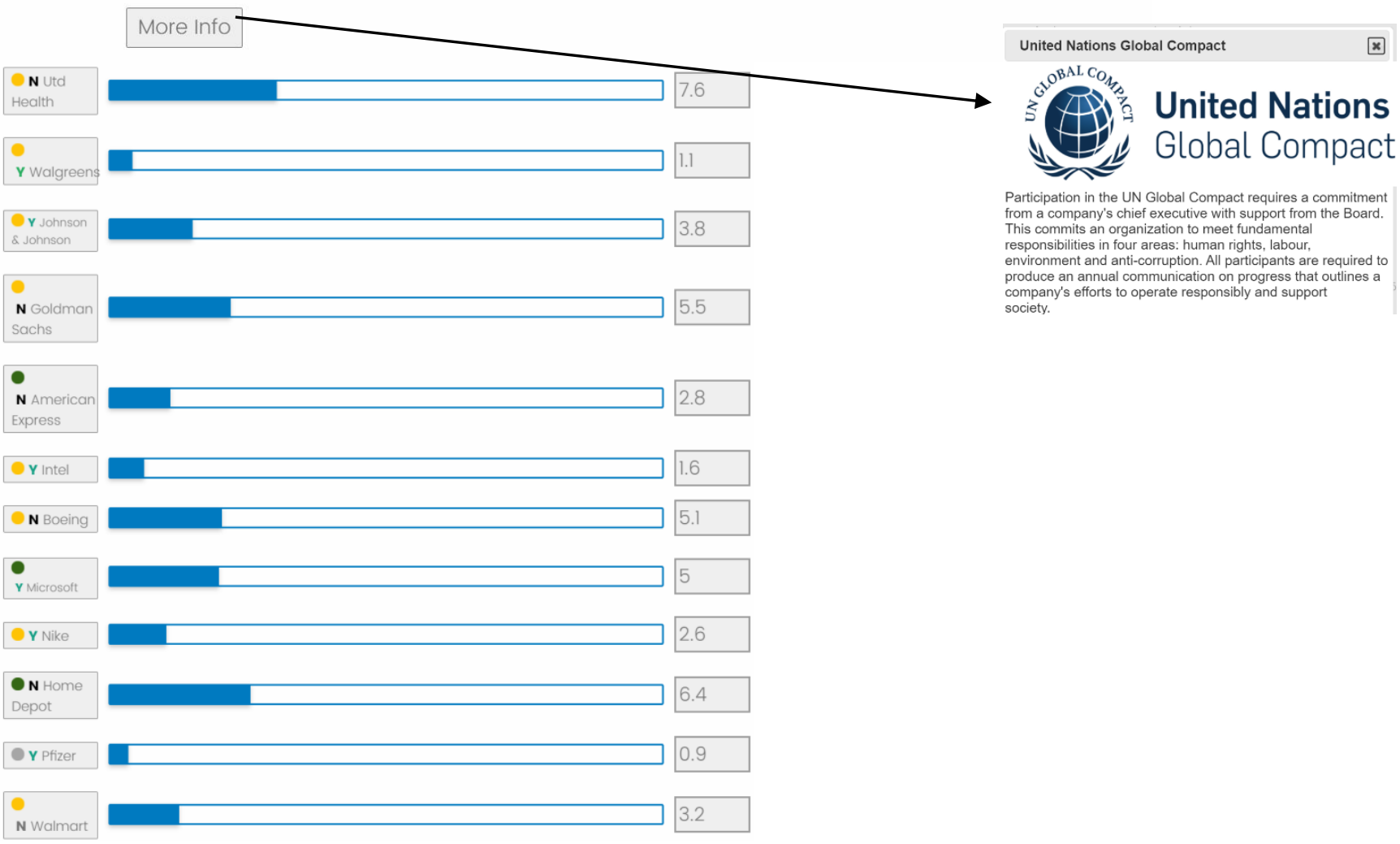




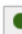
N Procter

$\delta$ Gamble

$$
\text { N }
$$$$
\text { N IBM }
$$$$
\text { Y } \operatorname{coc}
$$$$
\text { Cold }
$$$$
\begin{array}{|l|}
\hline \text { N Raytheon } \\
\text { Technologies } \\
\hline
\end{array}
$$$$
\text { N Caterpillar }
$$$$
\begin{aligned}
& \text { N Walt } \\
& \text { Disney }
\end{aligned}
$$$$
\begin{aligned}
& \text { N JPMorgar } \\
& \text { Chase } \\
& \hline
\end{aligned}
$$$$
\text { N Travelers }
$$$$
\square
$$

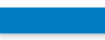

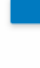$$
\text { प }
$$
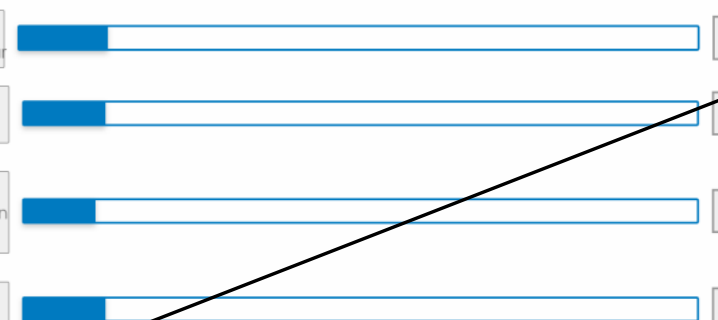
$y$ Y verizon<smiles>C1CCC1</smiles>

N Chevron

Y y cisco

Y Dow

- y $3 \mathrm{M}$

N Exxon

Mobil

\begin{tabular}{|l|}
\hline N McDonalds \\
\hline Y Merck \\
\hline
\end{tabular}

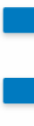

Total:
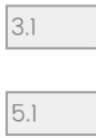

3.2
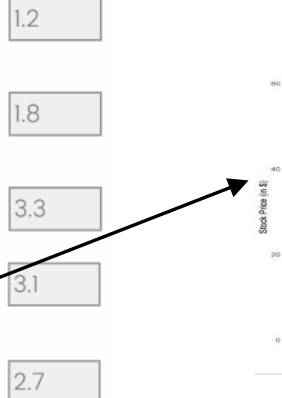

3.1

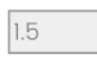

2.4

1.2

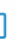

4.2
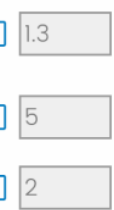

100.0
Verizon Communications, Inc.

Earnings per Share 2019: $\$ 4.65$

Free Cash Flow 2019 (in Bil): $\$ 17.81$

Dividends per share (Expected 2020): \$2.48

Industry: Diversified Telecommunication Services

Price / Book Ratio: 3.89

MSCI ESG Rating: $B B$ B

UN Global Compact Participant: Yes

Return graph past 5 years:

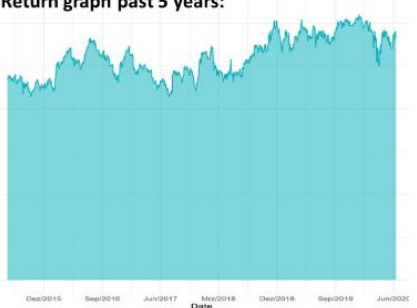

Example; Available for all stocks

\section{End of Block: Instructions 1}

Start of Block: Instructions 2 


\section{Instructions (2/3): Financial Advisor}

- You can either select stocks yourself, or you can take professional advice.

- If you decide for professional advice, we assign a financial advisor to you, who selects the stocks for you.

- The stock selection of the advisor will be based on your profile (age, income, gender) and on your investment preferences, which you can specify later.

- For constructing this stock portfolio, your financial advisor has set an advisory fee.

\section{Payment to you (if randomly selected):}

- You receive a base payment of $\$ 150$.

- Over the next year we will record the return of your stock portfolio (with a starting value of $\$ 1000)$.

- This return will be added to (if positive) or deducted from (if negative) your base payment.

- If you choose to take the advice of the financial advisor, an advisory fee will be deducted from your payment.

- If you choose to select the stocks yourself, no advisory fee will be deducted from your payment.

- You never owe us any money. If a negative stock return and the advisory fee exceed your base payment of $\$ 150$, you simply do not receive any money from us (Except for the survey completion fee).

- If you are randomly selected, you will be paid out one year after the survey is completed. Maastricht University and VU Amsterdam guarantee that all earnings will be paid out.

\section{Payment to your advisor:}

- If you take the advice, your advisor receives the advisory fee three weeks after this survey is completed

- If you choose to select the stock portfolio yourself, you will not receive any advice and your advisor receives no fee. 


\section{Instructions (3/3): Examples}

Example 1: You invest according to your advisor's suggestion. Your advisor has set an advisory fee of $\$ \mathrm{e}\{$ round( e://Field/Instr_Fee ,1 ) \}\%. After one year, the portfolio has generated a return of $\$ \mathrm{e}\{$ round( e://Field/Instr_Ret_Pos, 1 ) \}\%. If you are randomly selected, the following will be relevant for your payment:

- Your base payment of $\$ 150$.

- The advisory fee: $\$ 1,000^{*}(\$ \mathrm{e}\{$ round( e://Field/Instr_Fee, 1$\left.)\} \%\right)=\$ \$ \mathrm{e}\{$ round( e://Field/Instr_Fee, 1$\left.)^{*} 10\right\}$

- The return of the portfolio: $\$ 1,000^{*}(\$ e\{$ round( e://Field/Instr_Ret_Pos , 1 $\left.)\} \%\right)=\$ \$ e\{$ round( e://Field/Instr_Ret_Pos, 1$\left.){ }^{*} 10\right\}$.

- Hence, your total payout will be $\$ 150-\$ \$$ e $\{$ round( e://Field/Instr_Fee , 1 ) * 10$\}+\$ \$ e\{$ round( e://Field/Instr_Ret_Pos , 1$\left.){ }^{*} 10\right\}=\$ \$ \mathrm{e}\{(15-$ round( e://Field/Instr_Fee , 1$)+$ round( e://Field/Instr_Ret_Pos , 1$\left.)){ }^{*} 10\right\}$

Example 2: You invest according to your advisor's suggestion. Your advisor has set an advisory fee of $\mathrm{Se}\{$ round( e://Field/Instr_Fee ,1 ) \}\%. After one year, the portfolio has generated a return of $\$ \mathrm{e}\{$ round( e://Field/Instr_Ret_Neg , 1 ) \}\%. If you are randomly selected, the following will be relevant for your payment:

- Your base payment of $\$ 150$.

- The advisory fee: $\$ 1,000^{*}(\$ \mathrm{e}\{$ round( e://Field/Instr_Fee, 1$\left.)\} \%\right)=\$ \$ \mathrm{e}\{$ round( e://Field/Instr_Fee, 1$\left.)^{*} 10\right\}$

- The return of the portfolio: $\$ 1,000^{*}(\$ \mathrm{e}\{$ round( e://Field//nstr_Ret_Neg ,1 $\left.)\} \%\right)=\$ \$ \mathrm{e}\{$ round( e://Field/Instr_Ret_Neg ,1) *10\}

- Hence, your total payout will be $\$ 150-\$ \$ e\{$ round( e://Field/Instr_Fee , 1 ) * 10$\}+\$ \$ e\{$ round( e://Field/Instr_Ret_Neg ,1 $\left.{ }^{*} 10\right\}=\$ \$ e\{(15$ - round( e://Field/Instr_Fee , 1$)+$ round( e://Field/Instr_Ret_Neg, 1 )) $\left.{ }^{*} 10\right\}$

\section{End of Block: Instructions 3}

\section{Start of Block: Comprehension Questions}

\section{Comprehension Quiz}

- Please answer the questions below about the instructions on the previous screens.

- You have two chances to answer both comprehension questions correctly.

- If you fail to do so, you will not be able to complete the survey and you will not receive the completion fee of $\$ 2$. 
What is not a possible investment for you?

A stock portfolio that your advisor selects on your behalf

A stock portfolio that you select yourself

A savings account

Consider the following scenario. Your advisor set a fee of $\$ \mathrm{e}\{$ round( e://Field/Quiz_Fee ,1) $\} \%$. You decide to take the portfolio advice. The selected portfolio has a return of $\$ \mathrm{e}$ \{ round( e://Field/Quiz_Ret ,1 ) \}\%. How much will you be paid? Remember: Your base payment is $\$ 150$.

$\$ 0$

$\$ \$ e\{(15$ - round( e://Field/Quiz_Fee , 1 ) + round( e://Field/Quiz_Ret ,1 )) \}

$\$ \$ \mathrm{e}\{(15$ - round( e://Field/Quiz_Fee , 1 ) + round( e://Field/Quiz_Ret ,1 $\left.)){ }^{*} 10\right\}$

\section{End of Block: Comprehension Questions}

\section{Start of Block: Wrong Answer 1}

Wrong Answer (Only shown if there was a mistake in the comprehension questions)

At least one of your answers was not correct. Do you want to see the instructions again or would you like to retry answering?

See the instructions

Answer again 
Wrong Answer (Only shown if there was a mistake in the comprehension questions twice $\rightarrow$ End of Survey)

At least one of the answers you gave was not correct.

\section{End of Block: Wrong Answer 2}

\section{Start of Block: Advisor Mandate}

\section{Advisor mandate}

- Before you choose whether you like to receive advice, we have two questions.

- These questions will be used to match you to the right financial advisor.

Do you want to give your advisor a mandate for socially responsible investing? For all selectable stocks, your advisor will receive two indicators on the firm's social responsibility: MSCI ESG [Clickable button for more info] and the UN Global Compact [Clickable button for more info]. Should your advisor take these into account when selecting your stock portfolio?

Yes

No

How would you like your investment budget to be allocated between a savings account ( $0 \%$ interest rate) and a stock portfolio?

Aggressive (100\% in stocks)

Moderate $(50 \%$ in the savings account, $50 \%$ in stocks)

Conservative (100\% in the savings account)

\section{End of Block: Advisor Mandate}

\section{Start of Block: Allocation Decision}

\section{Investment Decision}

A financial professional put together a portfolio for a client with your profile. He or she set the 
following advisory fee for creating this stock portfolio.

Advisory Fee: $\$ \$\{$ e://Field/Fee $\} \%$

Would you like to invest in the stock portfolio that your advisor constructed on your behalf?

Yes, I will take the advice

No, I will select stocks myself

[Depending on their answer, participants are then either directly sent to the exit survey, or have to allocate their own stock portfolio]

\section{End of Block: Allocation Decision}

\section{Start of Block: Exit Survey (Demographics)}

Finally, last screen, please answer the following questions:

Which industry sector are you working in?

Agriculture, forestry \& fishing ... Transport 
How knowledgeable are you in financial matters?

\author{
Not knowledgeable \\ More or less knowledgeable \\ Knowledgeable \\ Very knowledgeable
}

What is the highest level of school you have completed or the highest degree you have received?

$\boldsymbol{\nabla}$ Less than high school degree ... Professional degree (JD, MD)

In which state do you currently reside?

Alabama ... I do not reside in the United States

Have you invested before, or are you planning to invest in the future (e.g., into stocks, bonds, investment funds, real estate)?
Yes
No 
Have you delegated investment decisions (e.g., purchase of stocks, bonds, investment funds, real estate) to financial advisors at banks or other institutions before?

$$
\begin{aligned}
& \text { Yes } \\
& \text { No }
\end{aligned}
$$

In general, how would you describe your own political viewpoint?

Very conservative ... Not sure

How willing are you to give to good causes without expecting anything in return?

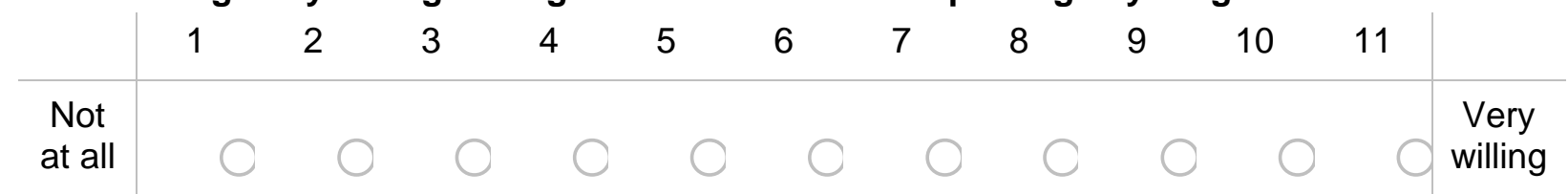

How much do you enjoy to take investment decisions?

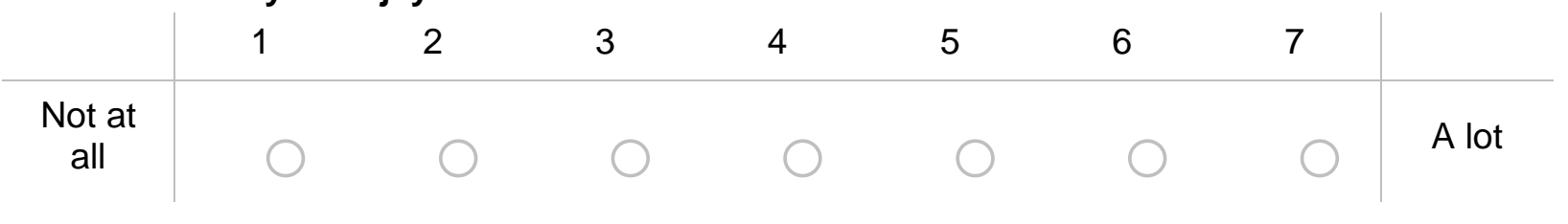

How much investment experience do you have?

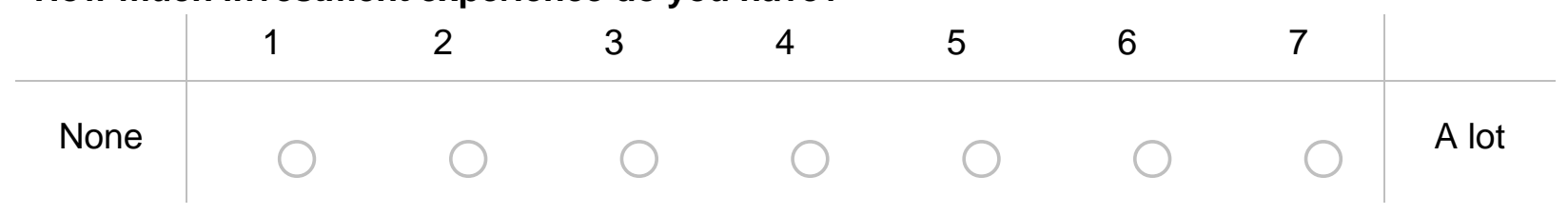


What yearly gross return do you expect to make on your selected stock portfolio? (In \%)

Less than $-15 \ldots$ More than 15

\section{End of Block: Exit Survey (Demographics)}

\section{Start of Block: PLEASE VISIT URL}

In about 3 weeks, you will be able to see proof of all stock transactions that we undertook to implement the portfolios. All data will be aggregated and anonymized, so that it is impossible to trace back any decision taken in the survey.

The information will be posted on this web page:

https://feedback001.wordpress.com/

Please write down the address of the web page if you want to visit it in 3 weeks.

Thank you very much for participating.

${ }^{* * *}$ Please click below to complete the survey ${ }^{* * *}$ 


\section{Selection Survey}

\section{Start of Block: Welcome Screen}

\section{Welcome}

Thank you for participating in the survey. Participation will take less than 10 minutes. Upon full completion of the survey you will receive a participation fee of $\$ 10$. You will receive your participation fee in points. All data will be depersonalized and will exclusively be used for the purpose of academic research.

${ }^{* * *}$ Please click below to start. Note that you will not be able to go back to previous pages throughout the whole study. ${ }^{* * *}$

\section{End of Block: Welcome Screen}

\section{Start of Block: SCREENER INDUSTRY}

Which industry sector are you working in?

$\nabla$ Agriculture, forestry \& fishing ... Transport

\section{End of Block: SCREENER INDUSTRY}

\section{Start of Block: SCREENER INVEST}

Which of the following best describes your current job?

\section{End of Block: SCREENER INVEST}


Imagine that you are considering purchasing stocks today, which you would like to sell twelve months from now. Please indicate how important each of the following information is for you when deciding on particular companies to invest in.

Please rank the following pieces of information, depending on how important they are in your decision process to invest in a particular stock. Drag the most important indicators to the top of the list and the least important indicators to the bottom.

Price range (last year)

Price chart (last 5 years)

Average price (expected by analysts next year)

Average price (last year)

Volatility (last year)

Dividends (last year)

Dividends (expected next year)

Industry

Previous day's trading volume

Previous year's trading volume

Market Capitalization

Price / Earnings Ratio (last year's earnings)

Earnings per share (last year)

Earnings per share (expected next year)

Price / Book Ratio

Annual Revenue (last year)

Revenue Growth (last 3 years)

Annual Profit (last year)

Free Cash Flow (last year)

Beta (last year)

Trade volume

Risk/return ratio, e.g., Sharpe ratio (last year)

Please specify any other indicators that we may have missed and that you consider to be part of the five most important pieces of information for your decision process to invest in a particular stock. 


\section{Start of Block: Sustainability Indicators}

In your investment decisions, do you consider any indicators on firms' abilities to meet environmental, social, and governance criteria?

Definitely yes ... Definitely not

How important are the following indicators in your decision-making?

\begin{tabular}{|c|c|c|c|c|c|c|c|}
\hline & $\begin{array}{l}\text { Not at all } \\
\text { important }\end{array}$ & Unimportant & $\begin{array}{l}\text { More or } \\
\text { less } \\
\text { unimportant }\end{array}$ & $\begin{array}{c}\text { Neither } \\
\text { important } \\
\text { nor } \\
\text { unimportant }\end{array}$ & $\begin{array}{l}\text { More or } \\
\text { less } \\
\text { important }\end{array}$ & Important & $\begin{array}{c}\text { Very } \\
\text { important }\end{array}$ \\
\hline $\begin{array}{c}\text { Thompson } \\
\text { Reuters ESG } \\
\text { Scores } \\
\text { (Asset4) }\end{array}$ & $\bigcirc$ & $\bigcirc$ & $\bigcirc$ & 0 & $\bigcirc$ & $\bigcirc$ & C \\
\hline $\begin{array}{l}\text { MSCI ESG } \\
\text { Rating }\end{array}$ & 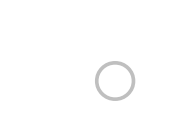 & $\bigcirc$ & $\bigcirc$ & O & $\bigcirc$ & O & \\
\hline $\begin{array}{l}\text { MSCI KLD } \\
\text { Scores }\end{array}$ & $\bigcirc$ & $\bigcirc$ & $\bigcirc$ & ○ & 0 & $\bigcirc$ & $\bigcirc$ \\
\hline $\begin{array}{c}\text { Sustainalytics } \\
\text { ESG Rating }\end{array}$ & O & $\bigcirc$ & $\bigcirc$ & O & & & \\
\hline
\end{tabular}

End of Block: Sustainability Indicators

Start of Block: Exit Survey non-demographics

Please answer the following questions: 
How would you rate your willingness to take risks ...

1: Not at all willing to take

2

3

4

5

7: Very risks

6 willing to take risks

generally in life:

$\ldots$ in financial matters:

How important is it for you to be the best at what you do?

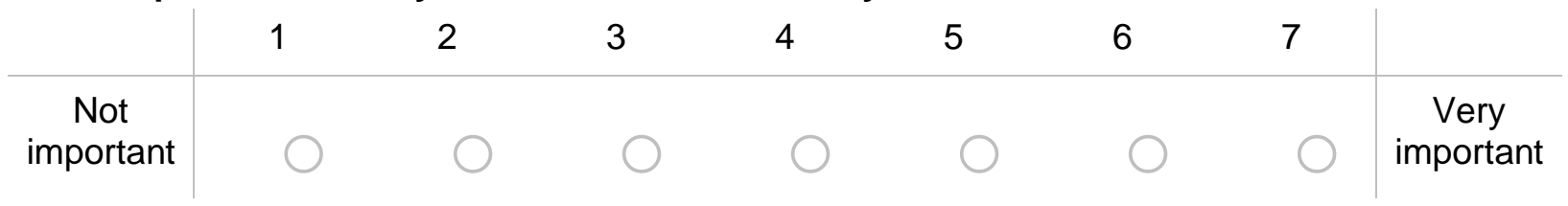

Social status is primarily defined by financial success.

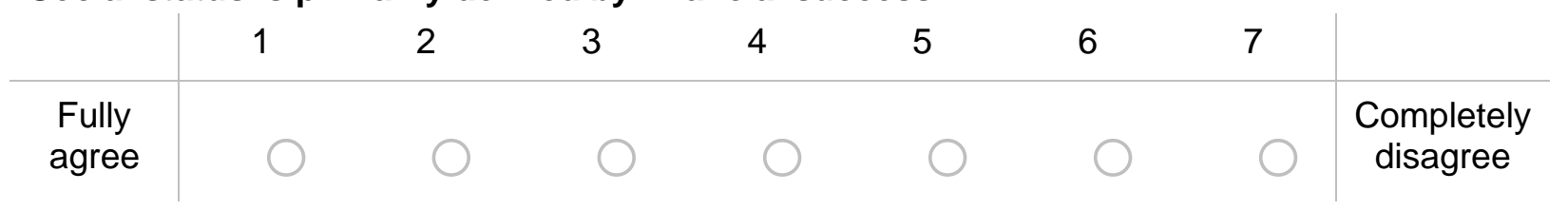

How important is it for you what others think about you?

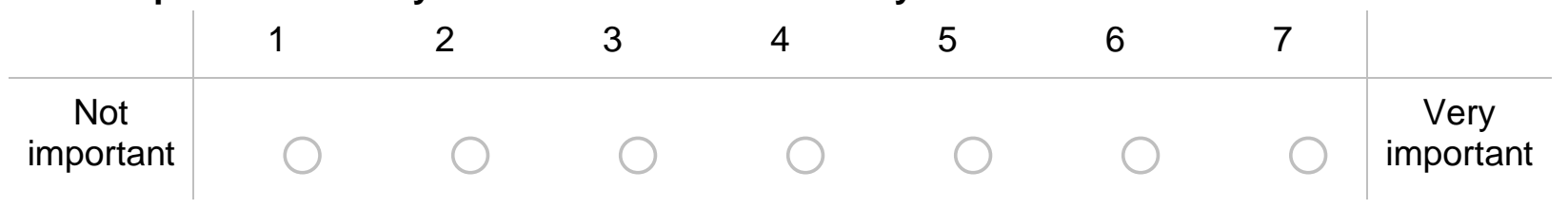


How willing are you to give to good causes without expecting anything in return?

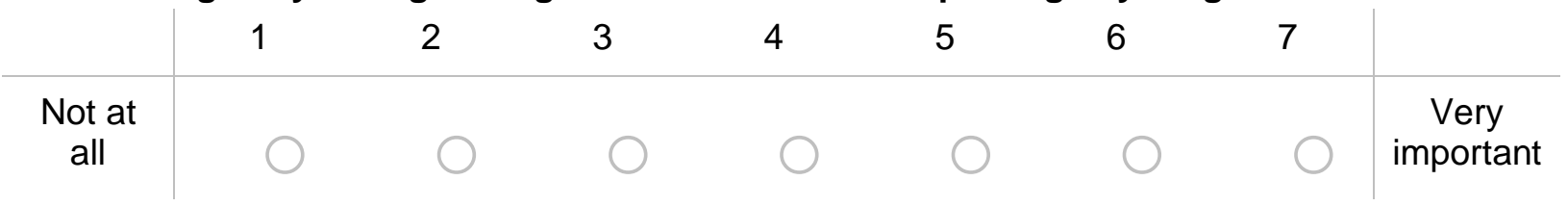

In general, how would you describe your own political viewpoint?

Very conservative ... Not sure

What is your present religion, if any?

$\nabla$ Protestant ... Other

How important is religion in your life?

Very important ... Not at all important

In our society there are groups which tend to be towards the top and groups which tend to be towards the bottom of the income scale.

If 1 equaled the bottom of the scale and 100 equaled the top of the scale, where would you put yourself now on this scale?

And where would you put the household you grew up in on the same scale? 
What has been the main source of your household's wealth?

Inheritance or family assets

Salary

Income from own business

Property

Lottery

Other (please specify)

End of Block: Exit Survey non-demographics

Start of Block: Exit survey demographics

Finally, last screen, please answer the following questions:

What is your gender?

Male

Female

Other

What is your age?

18 - 24 years old... 65 and older 
What is the highest level of school you have completed or the highest degree you have received?

Less than high school degree... Professional degree (JD, MD)

At which type of financial institution are you currently employed? (multiple answers possible)

What is the total amount your household donated to charitable causes last year (in \$)? If you are unsure, please make an estimate.

What was your gross combined, annual household income last year?

$\boldsymbol{\nabla}$ under $\$ 20,000 \ldots 200,000$ or more

How important are concerns for sustainability in your work?

Not at all important ... Very important

Does your current work contract include a bonus clause?

$$
\begin{aligned}
& \text { Yes } \\
& \text { No }
\end{aligned}
$$

\section{Display This Question:}


Did you receive a bonus in the last three years?

Yes

No

\section{Display This Question:}

If Does your current work contract include a bonus clause? = Yes

In relation to your fixed income, how large was the bonus payment? (If you received several bonuses, please state the average annual bonus payment.)

$\nabla$ less than $10 \%$ of fixed income... more than $500 \%$ of fixed income

\section{End of Block: Exit survey demographics}

\section{Start of Block: Thank you}

Thank you very much for participating.

*** Please click below to complete the survey *** 


\section{Regulators Survey}

\section{Start of Block: Welcome}

\section{Welcome}

Thank you very much for participating.

A few months ago we completed a research study with professional financial advisors in the United States.

- The research study investigated what fees advisors require

- for socially responsible and for conventional investment mandates

- from male and from female clients.

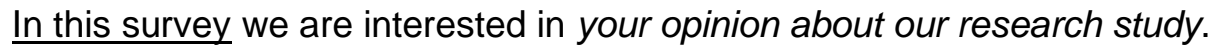

- Upon full completion of this survey (less than 11 minutes), you will

- receive early, preferential access to our research study results;

- you can earn $€ 20$, depending on the answers you give in this survey;

- make an important contribution to research.

All data will be depersonalized and will only be used for scientific purposes.

Thank you very much for participating!

- Marten Laudi (Maastricht University)

- Prof. Dr. Paul Smeets (Maastricht University)

- Prof. Dr. Utz Weitzel (VU Amsterdam, Radboud University)

${ }^{* * *}$ Please click below to start. ${ }^{* * *}$ 


\section{Description of the RESEARCH STUDY}

First, we will briefly describe the RESEARCH STUDY that we completed with financial advisors. You don't need to take any decisions in this part.

The goal of the RESEARCH STUDY was to find out:

- Whether financial advisors charge a different fee to clients who give them a mandate for socially responsible investing (SRI), than to clients who give them a conventional investing mandate.

- Whether financial advisors charge a different fee to female clients than to male clients.

\section{Background of the RESEARCH STUDY:}

- For that purpose, we ran an online experiment in which we matched real financial advisors with real clients, who invested real money to buy real stocks.

- We recruited $\mathbf{3 4 5}$ financial advisors in the US who are involved in managing or brokering financial assets on behalf of clients in their professional life.

- We included, for example, private bankers, investment advisors, and portfolio managers, but not IT support, auditors, or those working in corporate finance.

- We also recruited $\mathbf{3 4 5}$ individual clients in the US (not financial professionals), who were willing to invest $\$ 1000$ each (which we provided) in the stock market.

- We randomly matched each client with one financial advisor.

\section{Description of the RESEARCH STUDY}

Portfolio task for the financial advisor:

- In the experiment, each advisor was asked to manage the $\$ 1000$ stock portfolio of the matched client by weighting 30 stocks in the Dow Jones Industrial Average.

- Advisors saw some information about the client, including gender and a mandate from the client: (either a socially responsible investing (SRI) mandate, or a conventional mandate).

- We also provided the advisor with financial and SRI information for each stock.

Please click below to see an example of the client information and the portfolio task of the advisor.

Show an example of the portfolio allocation screen (Will be shown below)

\section{End of Block: description RESEARCH STUDY 1}




\section{Description of the RESEARCH STUDY}

After the portfolio task, each advisor was asked to set a fee for his/her service.

The advisor knew that clients were not obliged to accept the fee, because the clients could also choose to build their own portfolio.

EXAMPLE SCREEN for setting a fee by advisors: (Feel free to click on all buttons in the example)

[EXAMPLE SCREEN WAS DISPLAYED HERE]

\section{End of Block: description RESEARCH STUDY 2 and Example Screen Fee}

\section{Start of Block: description RESEARCH STUDY 3}

\section{Description of the RESEARCH STUDY}

Client decision:

- After the advisor had built a portfolio and set a fee, the matched client made a simple decision:

- Either: pay the fee as set by the advisor and use the advisor's portfolio.

- Or: do not pay the fee and build their own portfolio (without seeing the advisor's portfolio).

- In both cases the chosen portfolio was bought for real on the stock market and held for one year by the research team.

Payouts:

- If the client decided to pay a fee,

$\circ$ the advisor received the fee as a real payment,

$\circ$ and the client received the portfolio returns after one year after deduction of the fee.

- If the client decided against paying a fee,

o the advisor received nothing,

$\circ$ and the client received the raw portfolio returns after one year.

In all cases, the lowest possible payout for the client was 0 . 


\section{Comprehension Quiz RESEARCH STUDY}

- Please answer the two questions on the RESEARCH STUDY below:

What is not a possible investment for clients?

A stock portfolio that they select themselves

The stock portfolio that the advisor selects on their behalf

A savings account

Which was not a potential investment mandate that could be given by the client to the advisor?

A conventional investment mandate

A socially responsible investing mandate

A low-turnover investment mandate

[ON THIS PAGE, PARTICIPANTS RECEIVED FEEDBACK ON WHETHER THEY ANSWERED THE QUESTION CORRECTLY]

\section{End of Block: Comprehension Quiz}

\section{Start of Block: Prediction Fee short}

You have now finished the explanation, which is the largest part of the completion time.

Lets now start with your predictions.

When you finish this survey, we will randomly select one of your predictions.

If your prediction matches the actual findings from our study, you will receive $€ 20$.

[NOTE: THE ORDER OF THE QUESTIONS, AS WELL OF THE ORDER OF THE ANSWERS WERE RANDOMIZED] 


\section{Prediction: Fees by Gender}

- In the RESEARCH STUDY, the clients differed in terms of their gender.

- Who do you believe financial advisors charged a higher fee to in the RESEARCH STUDY?

Higher fee charged to male clients

Higher fee charged to female clients

$\underline{\text { No difference in fees }}$

\section{Prediction: Fees by Mandate}

- In the RESEARCH STUDY, the clients were able to give their advisor a mandate for socially responsible investing.

- Who do you believe financial advisors charged a higher fee to in the RESEARCH STUDY?

Higher fee charged to clients who gave a mandate for socially responsible investing

Higher fee charged to clients who gave a conventional investment mandate

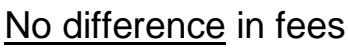

\section{End of Block: Prediction Fee short}

\section{Start of Block: Prediction Effort}

In the RESEARCH STUDY, we also measured advisors' effort exerted to construct a portfolio for each client.

Effort includes the time, as well as the number of clicks an advisor spent to construct a portfolio for a client.

[NOTE: THE ORDER OF THE QUESTIONS, AS WELL OF THE ORDER OF THE ANSWERS WERE RANDOMIZED] 


\section{Prediction: Effort by Gender}

- Who do you believe financial advisors exerted more effort for in the RESEARCH STUDY?

Higher effort exerted for male clients

Higher effort exerted for female clients

No difference in effort

\section{Prediction: Effort by Mandate}

- Who do you believe financial advisors exerted more effort for in the RESEARCH STUDY?

$\underline{\text { Higher effort exerted for clients who gave a mandate for socially responsible investing }}$

Higher effort exerted for clients who gave a conventional investment mandate

No difference in effort

\section{End of Block: Prediction Effort}

\section{Start of Block: External Validity of Findings}

Do you believe that the findings from our RESEARCH STUDY are informative about the behavior of financial advisors in the field?

...in the United States?
Not informative
Hardly informative
Somewhat informative
Informative
Very informative 
...in the European Union?

Not informative

Hardly informative

Somewhat informative

Informative

Very informative

\section{Page Break}

\section{End of Block: External Validity of Findings}

\section{Start of Block: Implications}

\section{Implications of our results}

Suppose the results of our RESEARCH STUDY would show that advisors charge higher fees to clients with a socially responsible investment mandate (vis-a-vis conventional mandates) without exerting any extra effort.

Do you think that such results from our RESEARCH STUDY would require attention from regulators?

Yes

No

\section{Page Break}

What do you think would be a suitable policy intervention? [ONLY SHOWN IF THE RESPONSE TO THE PREVIOUS QUESTION WAS YES] 
In the European Union, a forthcoming amendment to the Markets in Financial Instruments Directive II (MiFID II) will require financial advisors to ask clients whether they want to give an SRI mandate. Do you think that this regulation will be costly to asset managers?

No, asset managers will save money

No, it will not be costly

Yes, it will be costly

Yes, it will be very costly

If the MiFID II amendment turns out to be costly, who do you think should bear these additional costs?

Clients who give an SRI mandate

All clients

No client should bear these costs

\section{End of Block: Implications}

Start of Block: Exit survey

Finally, last screen, please answer the following questions:

What is your gender?

Male

Female

Other

Is socially responsible investing the main focus of your current work/function?

Yes

No 
What is your age?

$\nabla 18$ - 24 years old ... 65 and older

Compared to the average colleague in your organization, how much work experience do you have with projects/topics that are related to our experiment?

Far below average

Somewhat below average

Average

Somewhat above average

Far above average

What is the highest level of school you have completed or the highest degree you have received?

$\boldsymbol{\nabla}$ Less than high school degree ... Professional degree (JD, MD) 
Which of the following best describes your current job? (Multiple answers possible)

Regulation

Supervision

Policy work

Analysis

Research

Management

Teaching

Other (please specify below)

How much work experience do you have related to regulation and/or policy work in general? (Please enter years of experience)

If you want to receive early access to the results of the research study and be eligible for payment, please enter you email address below (optional).

Entering your email is completely voluntarily and the information will only be used for sending you early results and for payment. Your email address will be deleted from the raw data once we sent the results and completed the payments. After this, all data will be completely depersonalized and cannot be traced back to individuals. All data will be used for academic research purposes only. If you do not enter your email address we assume that you do not want to receive early results and that you also do not want to be eligible for any payment. 
Would you like to donate your earnings from this survey to a charitable organization?

Yes

No

Which organization would you like to donate to? [ONLY SHOWN IF THE RESPONSE TO THE PREVIOUS QUESTION WAS YES]

$\boldsymbol{\nabla}$ The Albert Schweitzer Foundation (Animal Welfare) ... Give Directly

End of Block: Exit survey

Start of Block: Thank You

Thank you very much for participating.

${ }^{* * *}$ Please click below to complete the survey ${ }^{* * *}$ 